Document downloaded from:

http://hdl.handle.net/10251/99147

This paper must be cited as:

Muller, J.; González Martínez, MC.; Chiralt A. (2017). Poly(lactic) acid (PLA) and starch bilayer films, containing cinnamaldehyde, obtained by compression moulding. European Polymer Journal. 95:56-70. doi:10.1016/j.eurpolymj.2017.07.019

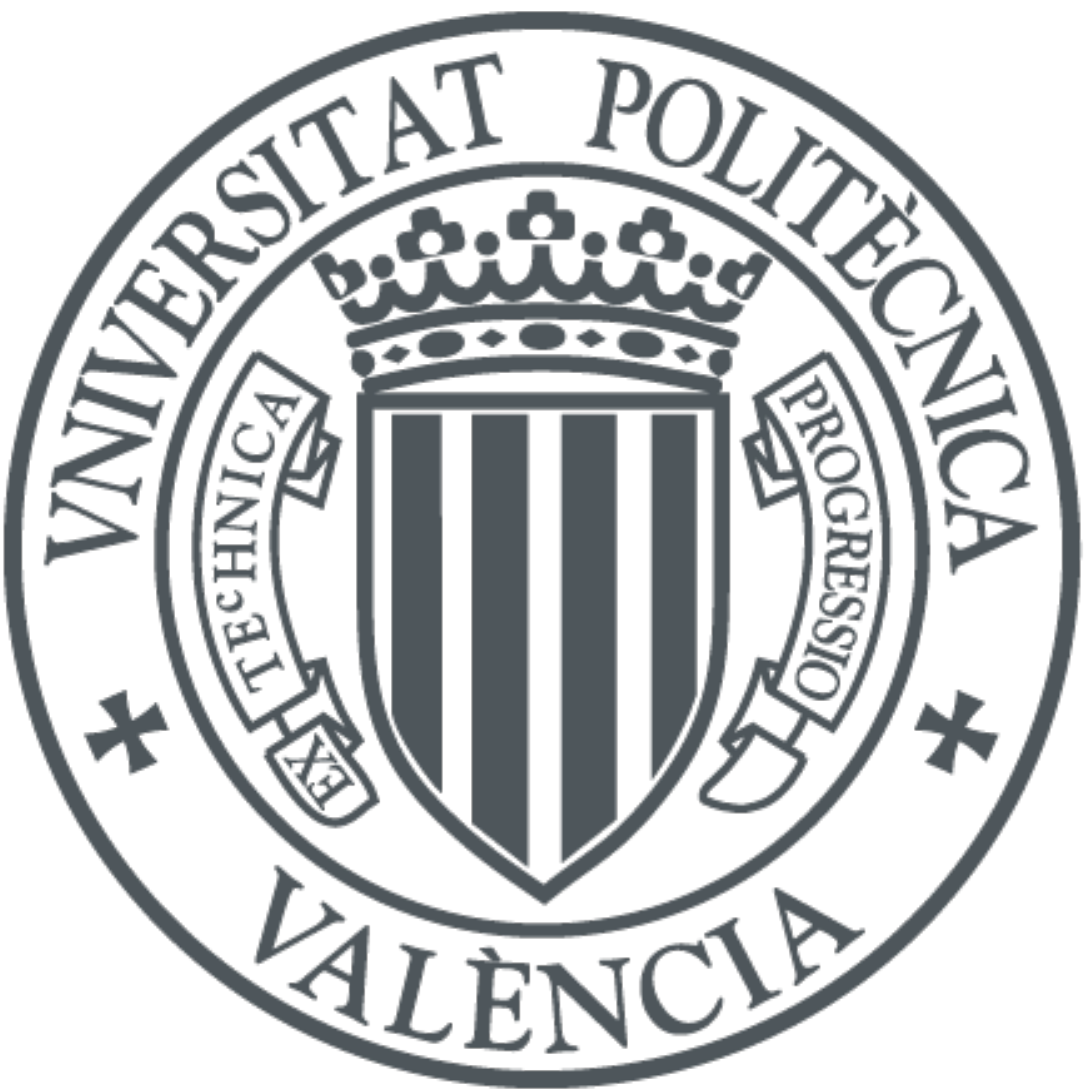

The final publication is available at

https://doi.org/10.1016/j.eurpolymj.2017.07.019

Copyright Elsevier

Additional Information 


\title{
Poly(lactic) acid (PLA) and starch bilayer films, containing cinnamaldehyde, obtained by compression moulding
}

\author{
Justine Muller, Chelo González, Amparo Chiralt \\ justinemuller@hotmail.fr, cgonza@tal.upv.es, dchiralt@tal.upv.es \\ Instituto Universitario de Ingeniería de Alimentos para su Desarrollo, Universidad Politécnica de Valencia, \\ Valencia, Spain.
}

\begin{abstract}
Bilayer films from thermoplastic starch and cast amorphous PLA were obtained by compression moulding, incorporating or not cinnamaldehyde in the PLA layer. Films were characterized as to their microstructure and barrier, tensile and optical properties, as well as thermal behaviour, X-Ray diffraction pattern and FTIR spectra. Bilayers using semicrystalline PLA, instead of starch, were also analysed for comparison purposes. Despite the lower ratio of cast PLA sheet in the bilayer assembly (about $1 / 3$ of the film thickness), a great improvement in tensile and water vapour barrier properties was achieved with respect to the net starch films, the films maintaining high transparency and oxygen permeability as low as starch films. When cinnamaldehyde was included in the cast PLA sheet, films became thinner due to the losses of the volatile active during processing, but the improvement in barrier properties was maintained, with lower mechanical resistance. Thermal analyses revealed diffusion of cinnamaldehyde or low molecular weight compounds from cast PLA layer to the adhered sheets (starch or semicrystalline PLA) which contributed to plasticizing the amorphous regions and affected crystallization pattern of PLA, as also revealed by the X-Ray diffraction patterns. The obtained results offer an interesting option to obtain high barrier-highly resistant active films from thermoplastic starch and amorphous PLA, including cinnamaldehyde as active compound.
\end{abstract}

\section{Key words}

Bilayer films, starch, poly(lactic) acid (PLA), cinnamaldehyde, tensile properties, barrier properties.

\section{INTRODUCTION}

Although petroleum-based plastics are still extensively used in the food packaging area, they represent one of the biggest environmental issues as regards the exhaustion of natural resources and the accumulation of non-biodegradable materials. The development of more ecological alternatives, reducing the amount of materials used for packaging or recycling are necessary to respond to this environmental problem. In this sense, bioplastics, that are either biodegradable or bio-based polymers, represent an adequate alternative. Although biopolymers do not exhibit excellent functional properties in terms of mechanical performance, thermal stability or barrier properties, they have been the subject of an increasing number of studies for the purposes of improving them, thus obtaining a functionality comparable to that of petrochemical plastics. One of the most promising biopolymers is poly(lactic) acid since it exhibits many advantages; it is biodegradable, renewable and biocompatible and has 
been approved by the Food and Drug Administration (FDA) for direct contact with biological fluids. It is highly transparent and exhibits good water vapour barrier properties [1], comparable to those of petroleum-based plastics, such as polyethylene terephthalate (PET) or polystyrene (PS). Nonetheless, PLA is highly hydrophobic, with limited gas barrier capacity and it is very brittle, with less than $10 \%$ of elongation at break [2]; [3]. In order to face these drawbacks, one of the many conceivable options is to combine it with other biopolymers with complementary properties. Starch is a good candidate since it is widely available and cheap, while its films are extensible with good oxygen barrier properties [4]. However, starch films exhibit poor water vapour barrier capacity, being very water sensitive, and are not a resistant material, with relatively low tensile strength [5]; [6]; [7]. Since PLA is highly hydrophobic and starch hydrophilic, it is difficult to blend both polymers without phase separation, so different strategies have been analysed to combine these materials. Either starch or PLA have been modified with plasma treatment [8]; [9] in order to modify their hydrophobicity. Different compatibilizers have also been used to enhance the interfacial interactions between both polymers [10]; [11]; [12]; [13]. However, there have been few studies into the obtaining of PLA-starch bilayer films. Sanyang et al. [14] characterized starch/PLA bilayers obtained by casting, with different ratios of both polymers, and found that these bilayers exhibit lower water vapour permeability and better mechanical performance than starch films. Indeed, since starch and PLA exhibit complementary properties in terms of the barrier capacity and the mechanical performance, their combination in bilayer assembly could offer adequate materials to meet the food packaging requirements. PLA exhibits good barrier capacity to water vapour and starch to oxygen. Although PLA is more brittle than starch, it exhibits a good resistance that can enhance the strength of PLA-starch bilayers. Besides, more and more of the food available in the stores comes in high-tech plastic packaging multilayer films, ensuring longer-term preservation of the food than a monolayer structure. Likewise, the incorporation of active compounds into starch/PLA bilayers could, moreover, yield an active biodegradable food packaging material with optimised functional properties. In this sense, cinnamaldehyde (CIN), one of the major constituents of cinnamon bark oil ( $60-90 \%)$ is a good option, since it has been classified as GRAS (Generally Recognized As Safe) by the FDA and it possess high antibacterial, antifungal, antiinflammatory and antioxidant activity [15]; [16]; [17]. Several studies have demonstrated that CIN could be potentially used, in different concentrations, as an effective antimicrobial agent, as observed by Baskaran et al. [18] for E. coli O157: H7 in apple juice and cider, by Amalaradjou et al. [19] for Enterobacter sakazakii in reconstituted milks or by Amalaradjou et al. [20] for E. coli in bovine meat pasties. CIN has also been included in different polymer matrices, such as PLA [21]; [22]; [23], starch [5], proteins [24] or alginates [25] to obtain active films.

Thus, the objective of this study was to analyse the functionality of starch-PLA bilayer films obtained by compression moulding as packaging material, and the effect of cinnamaldehyde incorporation on their properties. For comparison purposes, PLA-PLA bilayers were also studied. Likewise, microstructural and physical properties of the films were analysed as well as thermal behaviour and molecular interactions through FTIR spectra.

\section{MATERIALS AND METHODS}




\section{1. Materials}

PLA resins: semicrystalline PLA LL700, density of $1.25 \mathrm{~g} / \mathrm{cm}^{3}$, purchased from Ercros (Spain) and amorphous PLA 4060D, density of $1.24 \mathrm{~g} / \mathrm{cm}^{3}$, for heat seal layer in coextruded oriented films, purchased from Natureworks (U.S.A) were used to obtain films by compression moulding and casting method respectively. Cassava starch was produced by Asia CO., LDT (Kalasin, Thailand) and purchased from Quimidroga S.A. (Barcelona, Spain) and glycerol used as a plasticizer for starch was provided by Panreac Química SLU (Castellar del Vallés, Barcelona, España). Ethyl acetate, used as solvent for amorphous PLA, was obtained from Indukern S.A. (Barcelona, Spain) and transcinnamaldehyde and Poly(ethylene glycol) (PEG $4000 \mathrm{~g} / \mathrm{mol}$ ) were provided by Sigma-Aldrich (Madrid, Spain). For the quantification of cinnamaldehyde, pure methanol, UV-IR-HPLC quality, was obtained from Panreac (Barcelona, Spain). Magnesium nitrate $\left(\mathrm{Mg}\left(\mathrm{NO}_{3}\right)_{2}\right)$, used to reach a relative humidity $(\mathrm{RH})$ of $53 \%$ for the starch film conditioning, was supplied by Vidra Foc S.A. (Barcelona, Spain) and phosphorus pentoxide $\left(\mathrm{P}_{2} \mathrm{O}_{5}\right)$ was purchased from Panreac (Barcelona).

\section{2. Film preparation}

Thermoprocessed monolayer films of starch (S) or semicrystalline PLA and cast films of amorphous PLA, with or without cinnamaldehyde, were obtained and combined to obtain S-amorphous PLA and semicrystalline PLA-amorphous PLA bilayer films.

\section{2. 1. PLA monolayers obtained by casting ( $M$ and $M_{\text {cin }}$ )}

Amorphous PLA pellets were used to obtain PLA monolayers, with and without CIN, by casting method from the film forming dispersions. PLA pellets were first dried at $60^{\circ} \mathrm{C}$ overnight to remove residual water and then dissolved in ethyl acetate at $10 \%(\mathrm{w} / \mathrm{w})$ for 4 hours while being stirred at room temperature. CIN-free layers $(M)$ were obtained as control films and, in the case of active layers $\left(M_{\text {cin }}\right)$, CIN was dispersed at 2.5\%, which means a PLA:CIN ratio of 10:2.5. Dispersions were poured into 15 $\mathrm{cm}$ diameter Teflon plates at a solid surface density of $1.5 \mathrm{~g} / \mathrm{plate}$ and solvent was evaporated overnight. Dried films were peeled off the casting surface and stored in a desiccator with silica gel $\left(\mathrm{SiO}_{2}\right)$ at room temperature until further analysis or use to obtain bilayer films. The nominal concentration of CIN in dried films was $20 \mathrm{~g} / 100 \mathrm{~g}$. Ethyl acetate and amorphous PLA were chosen to prepare cast monolayers because this polymer can be adequately dissolved at room temperature in this food compatible solvent, thus minimising the risks of the solvent use, while cinnamaldehyde can also be incorporated in the solvent-polymer binary system.

\section{2. 2. PLA monolayers obtained by compression moulding (PLA)}

Semicrystalline PLA pellets were first dried at $60^{\circ} \mathrm{C}$ overnight and then hot-mixed in a two-roll mill (Model LRM-M-100, Labtech Engineering, Thailand) at $200^{\circ} \mathrm{C}$ and $10 \mathrm{rpm}$ for $10 \mathrm{~min}$. The resulting paste ( $3 \mathrm{~g}$ sample) was then compression moulded in a hydraulic press (Model LP20, Labtech Engineering, Thailand). The steel sheets were pre-heated at $200^{\circ} \mathrm{C}$ for 4 min and compression was performed at $200^{\circ} \mathrm{C}$ and 100 bars for $4 \mathrm{~min}$. A cooling cycle of $3 \mathrm{~min}$ until the temperature reached 
about $70^{\circ} \mathrm{C}$ was applied afterwards. The obtained films were maintained in a desiccator with $\mathrm{SiO}_{2}$ at room temperature until further analysis or use to obtain bilayer films.

\section{2. 3. Cassava starch monolayers obtained by compression moulding (S)}

Starch was first hand mixed with glycerol (30 g/100 $\mathrm{g}$ of starch), water (55 g/100 g of starch) and small amount of PEG (0,5 g/100 g starch). The dispersion was then melt blended in a two-roll mill at $160^{\circ} \mathrm{C}$ at $10 \mathrm{rpm}$ for $25 \mathrm{~min}$. The obtained thermoplastic starch was conditioned at $53 \% \mathrm{RH}$ (in a desiccator containing oversaturated solution of $\left.\mathrm{Mg}\left(\mathrm{NO}_{3}\right)_{2}\right)$ at room temperature for 10 days. Starch films were also obtained by compression moulding. $4 \mathrm{~g}$ of sample (3.56 g dry solids) were placed onto steel sheets and pre-heated in a hydraulic press at $160^{\circ} \mathrm{C}$ for $1 \mathrm{~min}$. Then, two step compression was performed at the same temperature; 50 bars for $2 \mathrm{~min}$, plus 100 bars for $6 \mathrm{~min}$. Afterwards, a cooling cycle of $3 \mathrm{~min}$ about $70^{\circ} \mathrm{C}$ was applied. The obtained films were maintained at $53 \% \mathrm{RH}$ at room temperature until further analysis or use to obtain bilayer films.

\section{2. 4. Starch (S-M, $\left.S-M_{\text {cin }}\right)$ and PLA bilayer films (PLA-M, PLA-M $\left.M_{\text {cin }}\right)$}

Bilayer films were obtained through thermocompression of the different monolayers. Either compression moulded PLA or S films were hot pressed with cast PLA films with and without CIN. Films were heated at $160^{\circ} \mathrm{C}$ and 100 bars for $3 \mathrm{~min}$ and cooled down until $70^{\circ} \mathrm{C}$ in $3 \mathrm{~min}$. The nominal mass fraction of cast PLA film in the bilayers was about 0.3. Films were maintained in a desiccator with $\mathrm{SiO}_{2}$ at room temperature until further analysis.

\section{3. Film characterization}

\section{3. 1. Quantification of cinnamaldehyde in the films}

The final CIN content in the films was determined by methanol extraction and spectrophotometric quantification. Film samples ( $1 \mathrm{~cm}$ side) were submitted to constant stirring for $24 \mathrm{~h}$ at $20^{\circ} \mathrm{C}$ in $100 \mathrm{~mL}$ of methanol. Then, absorbance was measured at $286 \mathrm{~nm}$ (maximum of absorption of the cinnamaldehyde in methanol) using a UV-visible spectrophotometer (Thermo Scientific Evolution 201, EEUU). The extract of the corresponding control film without CIN was used as a blank in each case. The calibration curve was obtained from the absorbance measurements of standard solutions of CIN and was used to determine its concentration in the films.

\section{3. 2. Film thickness}

A hand-held digital micrometer (Electronic Digital Micrometer, Comecta S.A., Barcelona, Spain) was used to measure film thickness to the closest $0.001 \mathrm{~mm}$, at six random positions around the film.

\section{3. 3. Microstructure}

The microstructural analysis of the cross-sections of the films was carried out by means of a Field Emission Scanning Electron Microscope (FESEM) (ULTRA 55, ZEISS, Germany). Film pieces, $0.5 \mathrm{x}$ $0.5 \mathrm{~cm}^{2}$ in size, were cryofractured with liquid nitrogen and fixed on copper stubs, platinum coated, 
and observed using an accelerating voltage of $2 \mathrm{kV}$. Observations were taken in duplicate for each formulation.

\section{3. 4. Tensile properties}

A texture analyser (TA-XT plus, STable Micro Systems, Surrey, United Kingdom) was used to measure the mechanical properties of films. Strips of films $(25 \mathrm{~mm}$ wide and $100 \mathrm{~mm}$ long) were mounted in the tensile grips (A/TG model) and stretched at a rate of $50 \mathrm{~mm} / \mathrm{min}$ until breaking. The elastic modulus (EM), tensile strength at break (TS) and percentage of elongation at break $(\varepsilon)$ were determined from stress-strain curves, obtained from force-deformation data. The experiments were carried out at $25^{\circ} \mathrm{C}$ and eight replicates were made for each film, according to the ASTM D882 method [26].

\section{3. 5. Barrier properties}

The water vapour permeability (WVP) of the films was measured using a modification of the ASTM E96-95 gravimetric method [27], using Payne permeability cups (Elcometer SPRL, Hermelle/s Argenteau, Belgium) of $3.5 \mathrm{~cm}$ diameter. For each formulation, the measurements were replicated four times and the WVP was calculated following the methodology described by Gennadios et al. [28] at $25^{\circ} \mathrm{C}$ and a $53-100 \% \mathrm{RH}$ gradient, which was generated using an oversaturated $\mathrm{Mg}\left(\mathrm{NO}_{3}\right)_{2}$ solution and pure distilled water, respectively. To determine the WVP, the cups were weighed periodically, using an analytical balance $( \pm 0.00001 \mathrm{~g})$, until the steady state was reached (about 2 and 5 days for $S$ and PLA films, respectively). The slope obtained from weight loss vs. time was used to calculate WVP, according to ASTM E96-95 [27].

Oxygen permeability (OP) of the films was determined by using the ASTM F1927 method [29], using OXTRAN SL $1 / 50$ MOCON equipment (U.S.A.). Measurements were taken in triplicate at $25^{\circ} \mathrm{C}$ and $50 \% \mathrm{RH}$. Film thickness was considered in all samples to obtain the OP values.

\section{3. 6. Optical properties}

The internal transmittance $\left(\mathrm{T}_{\mathrm{i}}\right)$ of the films was determined by means of a spectrocolorimeter (CM3600d, MinoltaCo., Tokyo, Japan) with a $10 \mathrm{~mm}$ diameter window. $T_{i}$ was obtained as an indicator of the transparency of the films, by applying the Kubelka-Munk theory [30] for multiple scattering to the reflection spectra, as described by Pastor et al. [31]. Four measurements per film formulation were carried out.

The gloss of the films was measured at a $60^{\circ}$ incidence angle, using a flat surface gloss meter (Multi.Gloss 268, Minolta, Germany), according to the ASTM standard D-523 [32]. Samples were measured over a black matte standard plate. Results were expressed as gloss units, relative to a highly polished surface of standard black glass with a gloss value close to 100 . Five replicates were made in three different films for each film formulation.

\section{3. 7. Thermal analysis}


Differential scanning calorimetry analyses were carried out using a DSC (1 StareSystem, MettlerToledo, Inc., Switzerland). Samples (5-10 mg) were placed into aluminium pans (Seiko Instruments, $\mathrm{P} / \mathrm{N} \mathrm{SSC000C008)}$ and sealed. Samples were heated from room temperature to $200^{\circ} \mathrm{C}$ at $10 \mathrm{~K} / \mathrm{min}$ in order to analyse phase transitions in the films. Samples were kept at $200^{\circ} \mathrm{C}$ for $5 \mathrm{~min}$, cooled to $-10^{\circ} \mathrm{C}$ at $-50 \mathrm{~K} / \mathrm{min}$, kept at $-10^{\circ} \mathrm{C}$ for $5 \mathrm{~min}$ and heated again to $200^{\circ} \mathrm{C}$ at $10 \mathrm{~K} / \mathrm{min}$; finally, they were cooled to $25^{\circ} \mathrm{C}$ at $-100 \mathrm{~K} / \mathrm{min}$. An empty aluminium pan was used as reference. Each sample was analysed in duplicate.

A thermo-gravimetric analyser (TGA/SDTA 851e, Mettler Toledo, Schwarzenbach, Switzerland) was used to characterize film thermal degradation. The analysis was performed from room temperature to $600^{\circ} \mathrm{C}$ at $10^{\circ} \mathrm{C} / \mathrm{min}$ under a nitrogen flow (50 $\mathrm{mL} / \mathrm{min}$ ). The initial degradation temperature (Tonset), i.e. the temperature at which $5 \%$ mass loss is registered, was recorded. The temperature at which the maximum degradation rate was observed $\left(T_{\max }\right)$ was also determined. Each sample was analysed in duplicate.

\section{3. 8. X-Ray diffraction (XRD)}

$X$-Ray diffraction analysis was performed on the films using a diffractometer (Bruker AXS/D8 Advance, Germany) at $40 \mathrm{kV}$ and $40 \mathrm{~m} \AA$. Scattered radiation was detected in an angular range of $5-50^{\circ}(2 \theta)$, at a step size of 0.05 .

\section{3. 9. Fourier Transform Infrared spectroscopy (FTIR)}

The vibration mode of the chemical groups in the films was assessed through attenuated reflectance ATR-FTIR analysis (Bruker, Tensor 27, Germany) within a wave range of $4000-400 \mathrm{~cm}^{-1}$. Samples were scanned 40 times with a resolution of $4 \mathrm{~cm}^{-1}$. Analyses were performed in triplicate on monolayers and on both sides of bilayer films.

\section{3.10. Molecular weight distribution in amorphous and semicrystalline PLA}

In order to analyse differences in the properties of amorphous and semi-crystalline PLA, the polymer molecular weight distribution was analysed by using a Waters HPLC 1525 chromatograph equipped with a Waters 996 PDA detector by using a GPC column Tosoh Bioscience TSKGEL GMHHR-H. Polymer samples were dissolved at $0.5 \%$ in chloroform and eluted with this solvent at $1 \mathrm{~mL} / \mathrm{min}$. To obtain the calibration curve, polystyrene standards (TSK Standard, Tosoh Corporation, Japan) of known molecular weight were used. From the obtained chromatograms, Mw (weight average molecular weight), Mn (number average molecular weight), Mp (Molecular weight at the maximum peak) and PI (Polydispersity index) were determined. Analysis of each polymer sample was carried out in duplicate.

\section{3. 11. Statistical analysis}

StaTgraphics Plus for Windows 5.1 (Manugistics Corp., Rockville, MD, U.S.A.) was used to carry out statistical analyses of data through an analysis of variance (ANOVA). Fisher's least significant difference (LSD) was used at the 95\% level. 


\section{RESULTS AND DISCUSSIONS}

\section{1. Film microstructure and cinnamaldehyde retention.}

The cross-section micrographs of monolayers and bilayers are showed in Figures 1 and 2, respectively. The starch micrograph did not show any granules, indicating the complete gelatinization of the polymer during thermal processing. Likewise, amorphous and semicrystalline PLA had a different appearance. Amorphous films exhibited the rubbery fracture, reflected in a higher frequency of stripes, whereas a rather brittle fracture was observed for semicrystalline PLA, exhibiting no plastic deformation. The incorporation of CIN to the PLA amorphous layer did not provoke appreciable structural changes.

In the bilayer films, the two different layers of amorphous PLA and starch or semicrystalline PLA are clearly appreciable, as is the good adhesion of respective monolayers. No layer detachment was observed for either S-M or PLA-M films, whether or not they contained CIN. This indicates a good compatibility of both S and semicrystalline PLA with the amorphous PLA which, in turn, showed a very different molecular weight distribution. Semicrystalline PLA had a monomodal distribution with $M p=134,778 D(M w=590,062 D, M n=43,997 D, P I: 13.4)$, whereas the amorphous polymer exhibited a bimodal distribution with $\mathrm{Mp}_{1}=80,016 \mathrm{D}$ and $\mathrm{Mp}_{2}=220 \mathrm{D}$; the latter peak was attributed to the plastizicing fraction in the sample. Therefore, the amorphous polymer had lower molecular weight $(M w=106,226 \mathrm{D}, \mathrm{Mn}=58,432 \mathrm{D}, \mathrm{PI}: 1.8)$ and contained $40 \%$ of a low molecular weight fraction (Mw= $275 \mathrm{D}, \mathrm{Mn}=54 \mathrm{D}, \mathrm{PI}: 5$ ), which exerts the plastizicing effect, thus contributing to the amorphous nature of the polymer. This low molecular weight fraction could positively affect the good layer adhesion at the interface of the bilayer films.

Noticeable differences in the thickness of the layers can be observed in the micrographs for both mono and bilayer films, as also shown in Table 1. Every film with CIN was thinner than the corresponding $\mathrm{CIN}$-free films. This difference points to the losses of the volatile compound both during the film preparation by casting and also during the thermocompression step of bilayers. In fact, a weight loss of $28.5 \%$ and $4.4 \%$, respectively for starch and PLA bilayers with CIN was observed during thermocompression. A part of the mass loss of starch bilayers must be attributed to the water evaporation of starch conditioned sheet ( $11 \%$ water content). The thickness reduction in $\mathrm{M}_{\text {cin }}$ layer with respect to the $M$ sample was about $9 \%$, which would correspond to losses of about $45 \%$ in the incorporated CIN during the casting-drying process. The ethanol extraction of CIN from this film only yielded $11.7 \pm 0.8 \mathrm{~g} / 100 \mathrm{~g}$ film, as opposed to the nominal concentration of $20 \%$, which represents losses in the same range as those estimated from the thickness reduction.

Likewise, the thickness of both bilayer sheets was reduced during thermocompression to a different extent, depending on the film. In fact, the overall measured thickness for bilayers was lower than the theoretical value (sum of each layer thickness). Two factors may contribute to this reduction: 1) flow of the sheets under pressure and heat in every case and 2) the losses of CIN when it was present in the films. The thickness reduction of each sheet in bilayers was estimated from the FESEM micrographs. For $S$ sheets, these reductions were 4 and 14\%, when adhered to $M$ and $M$ cin layers, respectively. For semicrystalline PLA sheets, these were 19 and 23\% when adhered to $M$ and $M_{c i n}$ layers, respectively. 
On the other hand, $\mathrm{M}$ and $\mathrm{M}_{\mathrm{cin}}$ sheets were reduced by 40 and 64\%, respectively, in $\mathrm{S}$ bilayers and by 13 and 32\%, respectively, in PLA bilayers. This indicates that the sheet flow was higher in the amorphous PLA layer, with or without CIN, followed by the semicrystalline PLA layer. CIN incorporation promoted the flow of both $S$ and semicrystalline PLA layers, which suggests the CIN diffusion into these matrices from $\mathrm{M}_{\text {cin }}$ produced a plastizicing effect. The great thickness reduction of the PLA amorphous layer without CIN indicates the great flowability of this plastiziced material. When it contained CIN, a greater thickness reduction was observed, due to both the enhancement of the material flowability by the CIN plasticization and to the additional losses of this compound during the thermocompression step. The greater reduction in $\mathrm{M}$ or $\mathrm{M}_{\mathrm{cin}}$ thickness that occurred when in contact with the starch was remarkable (40\%, without CIN), which points to additional plasticization efects associated with the migration of some compounds from the starch layer to the $\mathrm{M}$ layer. The ethanolextracted CIN from S and PLA bilayers yields 2.7 and $4.0 \mathrm{~g} / 100 \mathrm{~g}$ films, respectively. In contrast, the nominal CIN contents, estimated from the sheet weight ratio in the bilayer films, were 8.1 and 7.6 $\mathrm{g} / 100 \mathrm{~g}$ film, respectively. This indicates that greater losses of CIN occurred in the starch bilayers during thermocompression, which can be attributed to the steam drag effect associated with the water evaporation in the conditioned starch layer.
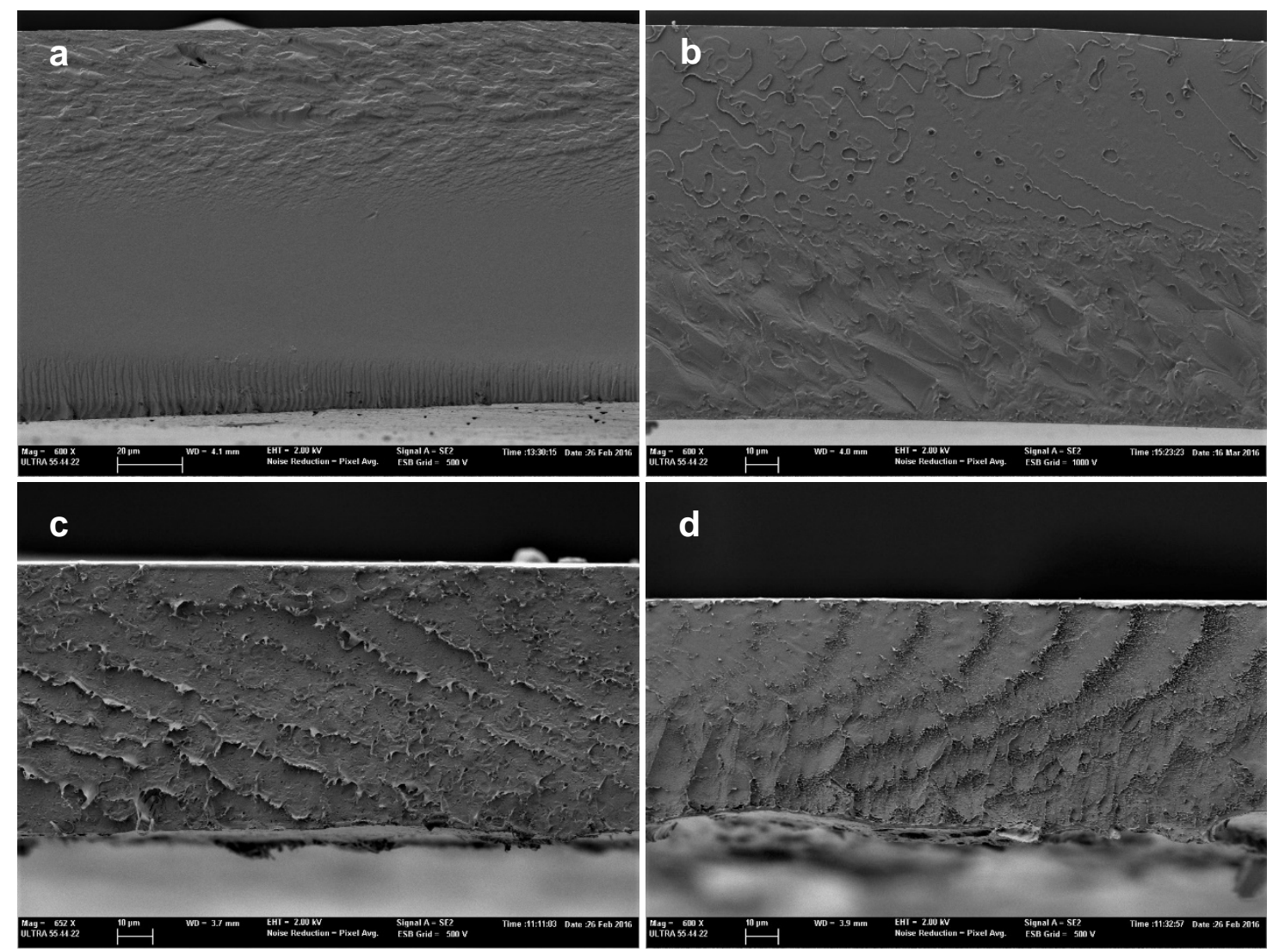

Figure 1. FESEM micrographs of cassava starch (S) (a) and PLA (b) monolayer films obtained by compression moulding and PLA films without (c) and with (d) cinnamaldehyde, obtained by the casting of ethyl acetate solutions. 

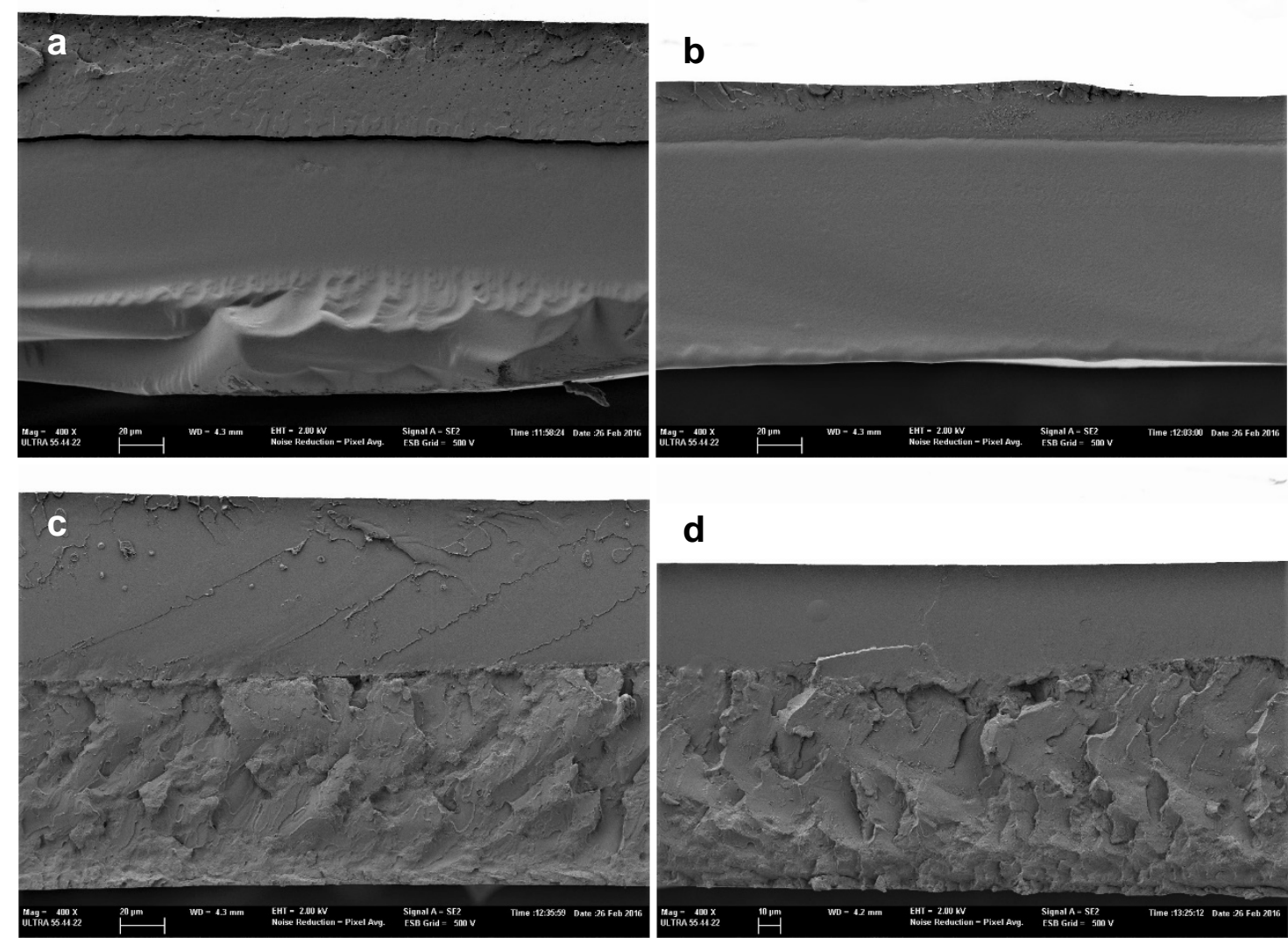

d

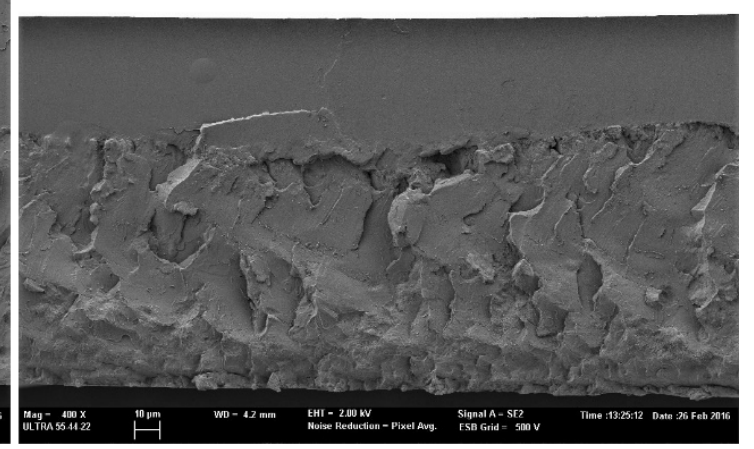

Figure 2. FESEM of the starch (top) and PLA (bottom) bilayer films without (left) and with cinnamaldehyde (right) obtained by compression moulding. Monolayers $\mathrm{M}$ and $\mathrm{M}_{\mathrm{cin}}$ appear at the top of bilayers.

\section{2. Physical properties}

Table 1 shows the tensile parameters of starch and PLA mono and bilayers: tensile strength (TS), Young modulus (EM) and percentage of elongation at break $(\varepsilon)$. It is noticeable that amorphous PLA $(M)$ is much more extensible than crystalline PLA, with Young's modulus reduced by five. This different behaviour is mainly due to both the differences in the polymer's molecular weight and the plasticizer effect, previously commented on. The processing method may also affect the film tensile behaviour. Indeed, films obtained by casting are more stretchable than those that are thermo-processed. Different authors [33]; [34]; [35]; [36] reported Young's modulus of 1300-3000 MPa for thermo-processed PLA as opposed to 600-950 MPa for cast PLA films [14]; [21]; [37]; [38]. Both amorphous and semicrystalline PLA were stiffer and more resistant to fracture than starch films, although the latter was more extensible than semicrystalline PLA. CIN incorporation in amorphous PLA caused a drop in both film stiffness and resistance to break in agreement with the weakening effect in the polymer matrix associated with the CIN interactions with the PLA chains, which limits the inter-chain forces.

When combining both types of PLA in bilayers, films exhibited a similar extensibility to semicrystalline PLA films, regardless of the presence of CIN, since this layer limits the extension capacity of bilayers. Nevertheless, the combination slightly reduced film stiffness, especially when CIN was present, while reducing resistance to break (by half) with respect to the semicrystalline PLA film. The greater 
reduction in the film stiffness when CIN was present could be due to the CIN diffusion into the semicrystalline layer, which weakened the PLA matrix by interfering with the chain associations. The reduction in the film's resistance to break (to a similar extent regardless of the presence of CIN) could be due to the rupture at the layer's interface level, where adhesion forces control the bilayer resistance.

For starch bilayers, a noTable increase in the film stiffness was observed with respect to the starch monolayer when there was not CIN in the bilayer, with no significant changes induced in the resistance and elongation at break. Nevertheless, when $\mathrm{M}_{\text {cin }}$ bilayer was considered, no changes in tensile behaviour were observed with respect to the starch monolayer. This indicates that, with the presence of CIN, the starch-PLA bilayer was not notably reinforced, as compared to net starch layers. In general, CIN incorporation slightly promoted the films' extensibility, while reducing the film's stiffness in both mono and bilayers. This points to its plasticizing effect, as reported by Ahmed et al. [21].

Table 1. Thickness, tensile parameters (TS, EM, $\varepsilon$ ), water vapour (WVP: $m \cdot g \cdot h^{-1} \cdot \mathrm{Pa}^{-1} \cdot \mathrm{m}^{-2}$ ) and oxygen permeability $\left(\mathrm{cm}^{3} \cdot \mathrm{m}^{-1} \cdot \mathrm{s}^{-1} \cdot \mathrm{Pa}^{-1}\right)$, internal transmittance $\left(\mathrm{T}_{i}\right.$ at $\left.600 \mathrm{~nm}\right)$ and gloss (at $60^{\circ}$ incidence angle) of films. Mean values \pm standard deviation. In bilayers, the mean gloss values for both sides of the films are shown, since no significant differences were detected between faces.

\begin{tabular}{ccccccccc}
\hline Film & Thickness $(\mathrm{mm})$ & TS (MPa) & EM (MPa) & $\varepsilon(\%)$ & WVP & OP $\times 10^{12}$ & $T_{i}(\%)$ & Gloss $60^{\circ}$ \\
\hline S & $0.155 \pm 0.008^{\mathrm{d}}$ & $4.1 \pm 0.4^{\mathrm{ab}}$ & $51 \pm 13^{\mathrm{a}}$ & $75 \pm 7^{\mathrm{c}}$ & $10.2 \pm 0.2^{\mathrm{c}}$ & $0.123 \pm 0.017^{\mathrm{a}}$ & $86.00 \pm 0.05^{\mathrm{a}}$ & $29 \pm 1^{\mathrm{b}}$ \\
PLA & $0.141 \pm 0.012^{\mathrm{c}}$ & $49 \pm 6^{\mathrm{e}}$ & $1599 \pm 64^{\mathrm{e}}$ & $3.5 \pm 0.5^{\mathrm{a}}$ & $0.088 \pm 0.008^{\mathrm{a}}$ & $15 \pm 1^{\mathrm{b}}$ & $88.88 \pm 0.02^{\mathrm{f}}$ & $22 \pm 3^{\mathrm{a}}$ \\
M & $0.085 \pm 0.006^{\mathrm{b}}$ & $71 \pm 6^{\mathrm{f}}$ & $298 \pm 86^{\mathrm{b}}$ & $174 \pm 5^{\mathrm{d}}$ & $0.132 \pm 0.009^{\mathrm{a}}$ & $41 \pm 7^{\mathrm{c}}$ & $88.1 \pm 0.4^{\mathrm{e}}$ & $75 \pm 3^{\mathrm{d}}$ \\
$\mathrm{M}_{\text {cin }}$ & $0.077 \pm 0.013^{\mathrm{a}}$ & $44 \pm 5^{\mathrm{d}}$ & $11 \pm 3^{\mathrm{a}}$ & $184 \pm 3^{\mathrm{d}}$ & $0.122 \pm 0.013^{\mathrm{a}}$ & $3.8 \pm 0.2^{\mathrm{a}}$ & $87.7 \pm 0.3^{\mathrm{cd}}$ & $75 \pm 5^{\mathrm{d}}$ \\
S-M & $0.205 \pm 0.013^{\mathrm{g}}$ & $6.7 \pm 1.4^{\mathrm{b}}$ & $248 \pm 65^{\mathrm{b}}$ & $52 \pm 19^{\mathrm{b}}$ & $0.43 \pm 0.05^{\mathrm{b}}$ & $0.18 \pm 0.09^{\mathrm{a}}$ & $86.56 \pm 0.02^{\mathrm{b}}$ & $30 \pm 2^{\mathrm{bc}}$ \\
S-M $_{\text {cin }}$ & $0.183 \pm 0.012^{\mathrm{e}}$ & $2.3 \pm 0.6^{\mathrm{a}}$ & $26 \pm 11^{\mathrm{a}}$ & $62 \pm 19^{\mathrm{b}}$ & $0.49 \pm 0.02^{\mathrm{b}}$ & $0.15 \pm 0.03^{\mathrm{a}}$ & $86.84 \pm 0.06^{\mathrm{b}}$ & $24 \pm 2^{\mathrm{a}}$ \\
PLA-M & $0.197 \pm 0.012^{\mathrm{f}}$ & $25 \pm 2^{\mathrm{c}}$ & $1487 \pm 44^{\mathrm{d}}$ & $1.9 \pm 0.3^{\mathrm{a}}$ & $0.097 \pm 0.009^{\mathrm{a}}$ & $4.0 \pm 0.7^{\mathrm{a}}$ & $87.4 \pm 0.2^{\mathrm{c}}$ & $32 \pm 2^{\mathrm{c}}$ \\
PLA-M $_{\text {cin }}$ & $0.188 \pm 0.013^{\mathrm{e}}$ & $24 \pm 4^{\mathrm{c}}$ & $1211 \pm 52^{\mathrm{c}}$ & $2.3 \pm 0.5^{\mathrm{a}}$ & $0.061 \pm 0.006^{\mathrm{a}}$ & $4 \pm 2^{\mathrm{a}}$ & $87.9 \pm 0.2^{\mathrm{de}}$ & $31 \pm 2^{\mathrm{bc}}$ \\
\hline
\end{tabular}

Different superscript letters within the same column indicate significant differences between formulations $(p<0.05)$.

As concerns the barrier properties, starch monolayers showed the highest WVP and the lowest OP as reported by several authors [5]; [39]; [40]. Amorphous PLA films exhibited less barrier capacity than semicrystalline PLA, both for water vapour and oxygen; the latter was greatly enhanced by CIN incorporation. This effect may be due to the antioxidant properties of CIN which provide it with an oxygen scavenging capacity, thus reducing OP, as previously observed for other antioxidants included in polymer films [41].

In starch bilayer films, WVP was greatly reduced with respect to starch films, as observed by Sanyang et al. [14] for starch-PLA bilayers, while OP had similar values to those of the starch monolayer. In PLA bilayers, the WVP was similar to that of the semicrystalline PLA film, while OP was significantly reduced. The incorporation of CIN did not notably change the WVP or OP in the bilayer films, despite the observed OP decrease in Mcin. The obtained results showed a great improvement in the barrier properties of starch-PLA bilayers, which represented a 96\% decrease in WVP with respect to the net 
starch films and a 99\% decrease in OP with respect to the amorphous PLA films. Then, the assembly of starch and amorphous PLA exhibited very good barrier capacity for both water vapour and oxygen, which confers them adequate functionality for food packaging applications, meeting the requirements of a wide range of food products [42]. Amorphous-semicrystalline PLA assembly exhibited good water vapour barrier capacity, but higher oxygen permeability. The incorporation of CIN into the amorphous PLA sheet in bilayers did not introduce WVP changes since it did not affect this property in $M_{\text {cin }}$; however, the oxygen scavenging effect observed in $\mathrm{M}_{\text {cin }}$ was not reflected in bilayers, probably due to the great reduction in OP induced by the PLA assembly. This could be explained by the formation of a less oxygen-permeable zone at the interface associated with strong polymer interactions, as observed in FESEM images.

As concerns the optical properties of the films, very similar values of Gloss and transparency were observed for the different mono and bilayers, except for cast PLA monolayers that exhibited higher gloss (Table 1). Gloss is directly related with the surface roughness of the films, whereas transparency, quantified by the internal transmittance $\left(T_{i}\right)$, depends on the internal microstructure of the matrix and the distribution of the components, which produced more or less light scattering. The surfaced roughness can be greatly influenced by the film processing and composition. Indeed, semicrystalline PLA and starch films, obtained by compression moulding, had the lowest gloss value. In the case of monolayers, CIN incorporation did not affect the gloss as the films already had a very smooth surface. Nevertheless, this gloss was greatly reduced after thermocompression in bilayers, where no significant differences were observed between the gloss values on each side of the films. The internal transmittance of the films was high in every case, between 86 and $89 \%$, which reveals a high degree of transparency and homogeneity. CIN incorporation barely changed $T_{i}$ in starch bilayers but slightly decreased it in monolayers, while it was noticeable that the $M_{\text {cin }}$ films were more yellowish than M films. It was shown that crystalline PLA films obtained by compression moulding were the most transparent, with a $T_{i}$ comparable to that of synthetic polymers, such as poly(ethylene terephthalate) (PET) and poly(styrene) (PS) [43]. As for the PLA bilayers, a slight decrease in the film transparency was noticeable in comparison with the monolayers, coinciding with their greater film thickness.

\section{3. Thermal properties}

Figure 3 shows the DSC thermograms of the different PLA-based films during the second heating scan. The absence of crystallization and melting in $M$ and Mcin films is noticeable, which is due to the amorphous character of the polymer, only exhibiting glass transition. Nevertheless, for semicrystalline PLA films in both mono and bilayers, a crystallization exotherm was observed after the glass transition, followed by the subsequent melting at about $170^{\circ} \mathrm{C}$, depending on the film. An excess enthalpy of relaxation $\left(\Delta \mathrm{H}_{\mathrm{ex}}\right)$ during the glass transition was also observed, as reported by other authors [44]; [45]. Likewise, another small exotherm prior to the melting endotherm appeared in mono and bilayer semicrystalline PLA films. This is associated with the $\alpha-\alpha$ ' phase transition at $\sim 160-165^{\circ} \mathrm{C}$, as reported by several authors [1]; [46]. Table 2 shows the temperature and enthalpy of the different thermal events observed in every mono and bilayers during the second heating step, where the previous thermal history of the samples has been deleted and all samples were submitted to the same 
heating-cooling cycles. The glass transition temperature $\left(T_{g}\right)$ of starch was in the range previously reported by other authors [47] and it decreased $\left(\Delta \mathrm{Tg} \approx 27^{\circ} \mathrm{C}\right)$ in S-Mcin bilayers, thus indicating the CIN diffusion into the starch layer and its plasticizing effect, as previously pointed out from FESEM observations. This CIN plasticizing effect was also observed in amorphous PLA monolayer $\left(\Delta \mathrm{Tg} \approx 7^{\circ} \mathrm{C}\right)$ and in PLA bilayers $\left(\Delta \mathrm{Tg} \approx 16^{\circ} \mathrm{C}\right)$. A similar effect of CIN was observed by Ahmed et al. [48] in PLA/PEG blend films and by Qin et al. [23] in PLA/poly(trimethylene carbonate) films. Semicrystalline PLA had a higher $T_{g}$ value than the amorphous one, according to the higher molecular weight of the semicrystalline product. However, in PLA bilayers, only one glass transition was appreciated to be closer to that of the semicrystalline fraction, according to its higher mass fraction in bilayer films and the potential diffusion of the low molecular plasticizing fraction of the amorphous product, which could also plasticize the semicrystalline layer. Indeed, the crystallization of PLA was also affected by its assembly with the amorphous PLA monolayer, mainly when this contained CIN. The crystallization temperature $\left(T_{c}\right)$ drops by about 3 and $14^{\circ} \mathrm{C}$ in PLA bilayers without and with CIN, respectively, while the crystallinity degree $\left(X_{c}\right)$ of PLA in the films decreased from about 27 to 8 and $5 \%$ in PLA bilayers, without and with CIN respectively. This behaviour also agrees with a greater plasticization of semicrystalline PLA in bilayer films due to the diffusion of either low molecular compounds from amorphous PLA layer or CIN. After glass transition, the decrease in $T_{c}$ during the heating step of bilayers points to a faster crystallization, due to the fact that there is greater molecular mobility in the polymer in the more plasticized system. However, the melting behaviour of PLA in bilayers points to a less cohesive crystalline zone (lower $T_{m}$ and $\Delta H_{m}$ ), which suggests that the migrated compounds from the amorphous layer interfered with the crystalline arrangement, leading to an apparently lower degree of crystallinity $\left(X_{c}\right)$ in the semicrystalline layers.

Thus, the thermal analysis of the films revealed that CIN diffuses into the starch and PLA sheets in bilayer films, significantly decreasing the $T_{g}$ of both starch and semicrystalline PLA and also enhancing the PLA crystallization kinetics (lower $T_{c}$ ), but reducing the final degree of crystallinity in the semicrystalline layer. 


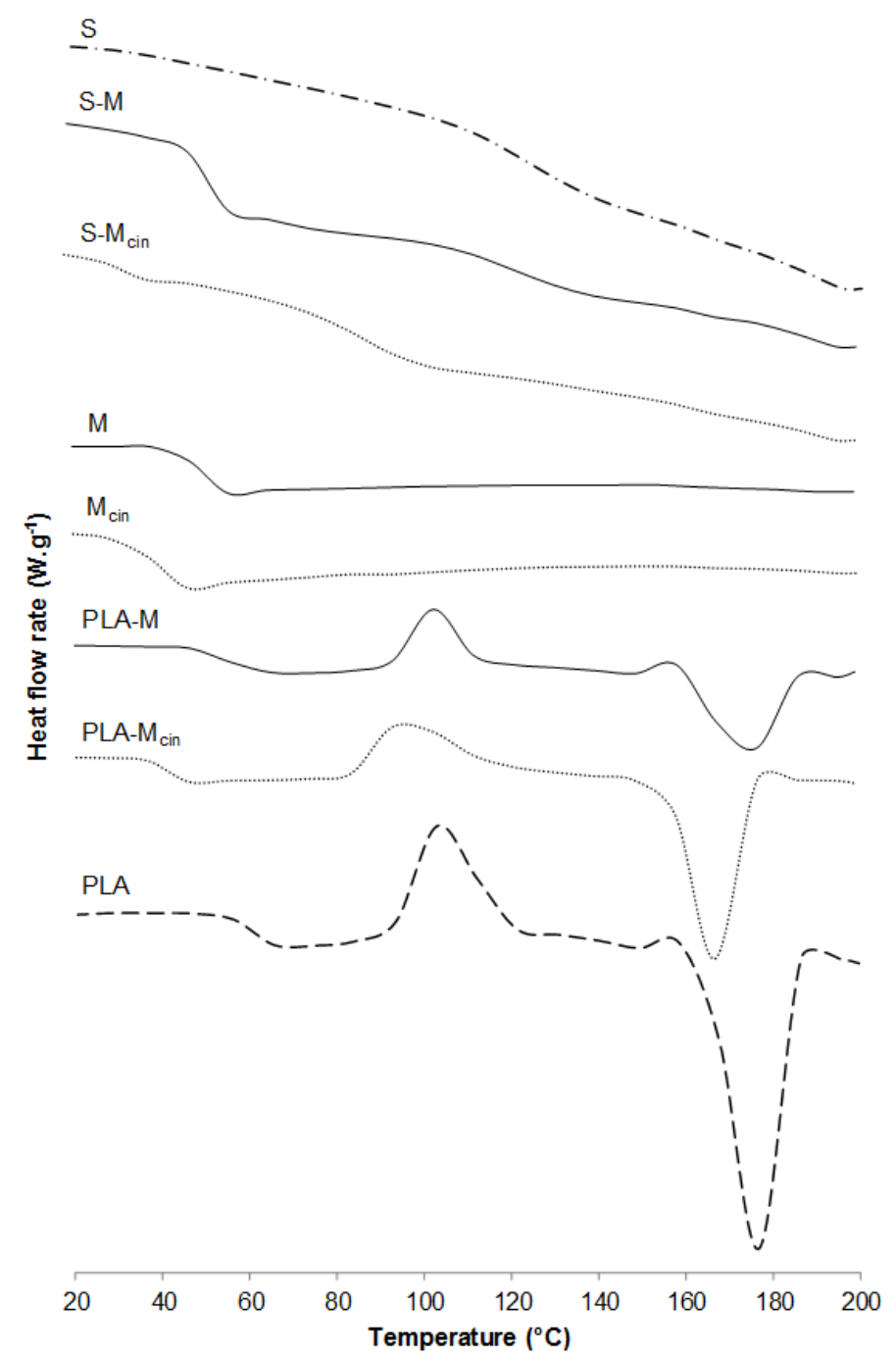

Figure 3. DSC thermograms of monolayers (, PLA, $M, M_{\text {cin }}$ ) and bilayers (S-M, S-Mcin, PLA-M, PLAMcin) from the second heating step.

Table 2. Thermal properties of films obtained by DSC (second heating scan). Mean values \pm standard deviation. PLA enthalpy values are expressed per $g$ of semicrystalline PLA in bilayers.

\begin{tabular}{|c|c|c|c|c|c|c|c|c|}
\hline Film & $\mathrm{T}_{\mathrm{g}} \mathrm{S}\left({ }^{\circ} \mathrm{C}\right)$ & $\mathrm{T}_{\mathrm{g}} \mathrm{PLA}\left({ }^{\circ} \mathrm{C}\right)$ & $\Delta \mathrm{H}_{\mathrm{ex}}(\mathrm{J} / \mathrm{g} \mathrm{PLA})$ & $\mathrm{T}_{\mathrm{c}}\left({ }^{\circ} \mathrm{C}\right)$ & $\Delta \mathrm{H}_{\mathrm{c}}(\mathrm{J} / \mathrm{g} \mathrm{PLA})$ & $\mathrm{T}_{\mathrm{m}}\left({ }^{\circ} \mathrm{C}\right)$ & $\Delta \mathrm{H}_{\mathrm{m}}(\mathrm{J} / \mathrm{g} \mathrm{PLA})$ & $\mathrm{X}_{\mathrm{c}}(\%)$ \\
\hline $\mathrm{S}$ & $120.4 \pm 0.3^{b}$ & n.d. & n.d. & n.d. & n.d. & n.d. & n.d. & n.d. \\
\hline PLA & n.d. & $58.7 \pm 0.2^{d}$ & $0.28 \pm 0.08^{a}$ & $107.0 \pm 0.2^{b}$ & $31 \pm 1^{c}$ & $174.8 \pm 0.2^{b}$ & $57.1 \pm 0.4^{b}$ & $27 \pm 1^{b}$ \\
\hline$M$ & n.d. & $44 \pm 5^{b}$ & $0.8 \pm 0.3^{b}$ & n.d. & n.d. & n.d. & n.d. & n.d. \\
\hline $\mathrm{M}_{\text {cin }}$ & n.d. & $37 \pm 1^{a b}$ & $0.8 \pm 0.2^{b}$ & n.d. & n.d. & n.d. & n.d. & n.d. \\
\hline S-M & $123 \pm 3^{b}$ & $50.62 \pm 0.06^{c}$ & $0.22 \pm 0.02^{a}$ & n.d. & n.d. & n.d. & n.d. & n.d. \\
\hline $\mathrm{S}-\mathrm{M}_{\mathrm{cin}}$ & $93 \pm 3^{a}$ & $31 \pm 1^{a}$ & n.d. & n.d. & n.d. & n.d. & n.d. & n.d. \\
\hline PLA-M & n.d. & $55.34 \pm 0.04^{\mathrm{cd}}$ & $0.14 \pm 0.02^{a}$ & $103.8 \pm 0.2^{b}$ & $13 \pm 1^{a}$ & $174.6 \pm 0.4^{b}$ & $20.8 \pm 0.5^{a}$ & $8 \pm 1^{a}$ \\
\hline PLA-M ${ }_{\text {cin }}$ & n.d. & $39 \pm 5^{b}$ & $0.24 \pm 0.05^{a}$ & $93 \pm 3^{a}$ & $18.6 \pm 0.2^{b}$ & $165 \pm 4^{a}$ & $24 \pm 2^{a}$ & $5 \pm 2^{a}$ \\
\hline
\end{tabular}

$\mathrm{X}_{\mathrm{c}}=\left(\Delta \mathrm{H}_{\mathrm{m}}-\Delta \mathrm{H}_{\mathrm{c}}\right) / \Delta \mathrm{H}_{0}$; with $\Delta \mathrm{H}_{0}=96 \mathrm{~J} / \mathrm{g}$ crystalline PLA (value from Kalish et al. [49]) n.d.: Non-detected

Different superscript letters within the same column indicate significant differences between formulations $(p<0.05)$. 
Thermogravimetric analysis (TGA) also revealed differences in polymer thermodegradation associated with the compression moulding of bilayers and the presence of $\mathrm{CIN}$. Table 4 presents the onset ( $\mathrm{T}_{\text {onset }}$ ) and maximum degradation rate ( $\left.T_{\max }\right)$ temperature values of films, while the TGA curves from 25 to $600^{\circ} \mathrm{C}$ are shown in Figure 4.a). The Tonset of semicrystalline PLA was found to be around $320^{\circ} \mathrm{C}$, with a total weight loss in a single step (maximum at $333^{\circ} \mathrm{C}$ ), as observed by Muller et al. [1], this polymer being the most thermally sTable of the studied matrices. In all of the other films, two weight losses could be observed. The first one corresponds to water (in the case of $\mathrm{S}$ mono and bilayers) and/or CIN losses (in the films carrying the active compound), whereas the second most intense weight loss, occurring in a temperature range of $264-320^{\circ} \mathrm{C}$ (depending on the film), corresponds to the polymer matrix decomposition. A slight weight loss $(5.2 \%)$ is also noticeable between 40 and $85^{\circ} \mathrm{C}$ in the amorphous PLA film (M), which can be associated with the degradation/vaporization of some molecular weight compounds present in the polymer, which were delayed in the $M_{\text {cin }}$ films $\left(\sim 100^{\circ} \mathrm{C}\right)$, thus indicating interactions between CIN and these compounds. In fact, a DSC analysis of $\mathrm{M}_{\text {cin }}$ exhibited a small, broad exothermic peak between $70-200^{\circ} \mathrm{C}$, which could be associated with the enthalpy reaction of $\mathrm{CIN}$ with some low molecular weight compounds present in the amorphous PLA. This peak did not appear in the second heating scan nor in bilayer films containing $\mathrm{CIN}$, because the previous thermal treatment would already have promoted this reaction. In every case, the incorporation of $\mathrm{CIN}$ led to a progressive, slow weight loss from about $120^{\circ} \mathrm{C}$, which was more marked in $\mathrm{M}_{\text {cin }}$ samples with the highest mass fraction of CIN. This also affected the Tonset of films, with PLA monolayers exhibiting the most significant difference, from 316 to $305^{\circ} \mathrm{C}$. Starch films were the least thermally sTable in comparison with amorphous and semicrystalline PLA; the degradation step took place between 275 and $310^{\circ} \mathrm{C}$, as reported by other authors [50]; [14]. Then, due to starch being less thermally sTable, the bilayers showed lower $T_{\text {onset }}\left(268^{\circ} \mathrm{C}\right)$ and exhibited two degradation steps, as shown more clearly in Figure 4.b), through the first derivative of the TGA curves. S-M bilayers presented two well-defined peaks, related to the first degradation of the starch fraction and the subsequent degradation of the PLA fraction. However, when CIN was present, the second degradation step appeared as a shoulder, according to the lower ratio of the PLA layer, as deduced from FESEM images. No different steps were observed either for amorphous or semicrystalline PLA bilayers in line with the similar degradation behaviour of both amorphous and semicrystalline PLA.

Table 3. Thermal degradation temperatures (onset value $T_{\text {onset }}$ and value at maximum degradation rate $\left.T_{\max }\right)$ of the different films and of cinnamaldehyde $(\mathrm{CIN})$ obtained by TGA. Mean values \pm standard deviation. 


\begin{tabular}{cccc}
\hline Film & $\mathrm{T}_{\text {onset }}\left({ }^{\circ} \mathrm{C}\right)$ & $\mathrm{T}_{\max }\left({ }^{\circ} \mathrm{C}\right)$ & Weight loss (\%) \\
\hline S & $275 \pm 3^{\mathrm{c}}$ & $285.0 \pm 0.2^{\mathrm{bc}}$ & $91 \pm 3^{\mathrm{a}}$ \\
PLA & $320.0 \pm 0.3^{\text {ef }}$ & $333.0 \pm 0.2^{\mathrm{f}}$ & $100.0 \pm 0.0^{\mathrm{b}}$ \\
$\mathrm{M}$ & $316 \pm 2^{\mathrm{e}}$ & $329.7 \pm 0.5^{\mathrm{de}}$ & $100.0 \pm 0.0^{\mathrm{b}}$ \\
CIN & $208 \pm 3^{\mathrm{a}}$ & $217.9 \pm 0.2^{\mathrm{a}}$ & $100.0 \pm 0.0^{\mathrm{b}}$ \\
$\mathrm{M}_{\text {cin }}$ & $305 \pm 3^{\mathrm{d}}$ & $328 \pm 2^{\mathrm{d}}$ & $100.0 \pm 0.0^{\mathrm{b}}$ \\
S-M & $268 \pm 2^{\mathrm{b}}$ & $286.8 \pm 0.8^{\mathrm{c}}$ & $90.4 \pm 0.5^{\mathrm{a}}$ \\
S-M & $264 \pm 2^{\mathrm{b}}$ & $284 \pm 2^{\mathrm{b}}$ & $89.8 \pm 0.9^{\mathrm{a}}$ \\
PLA-M & $320.1 \pm 0.5^{\mathrm{f}}$ & $335.3 \pm 0.4^{\mathrm{g}}$ & $100.0 \pm 0.0^{\mathrm{b}}$ \\
PLA-M $_{\text {cin }}$ & $316.4 \pm 0.9^{\text {ef }}$ & $331.5 \pm 0.9^{\text {ef }}$ & $100.0 \pm 0.0^{\mathrm{b}}$ \\
\hline
\end{tabular}

Different superscript letters within the same column indicate significant differences between formulations $(p<0.05)$.

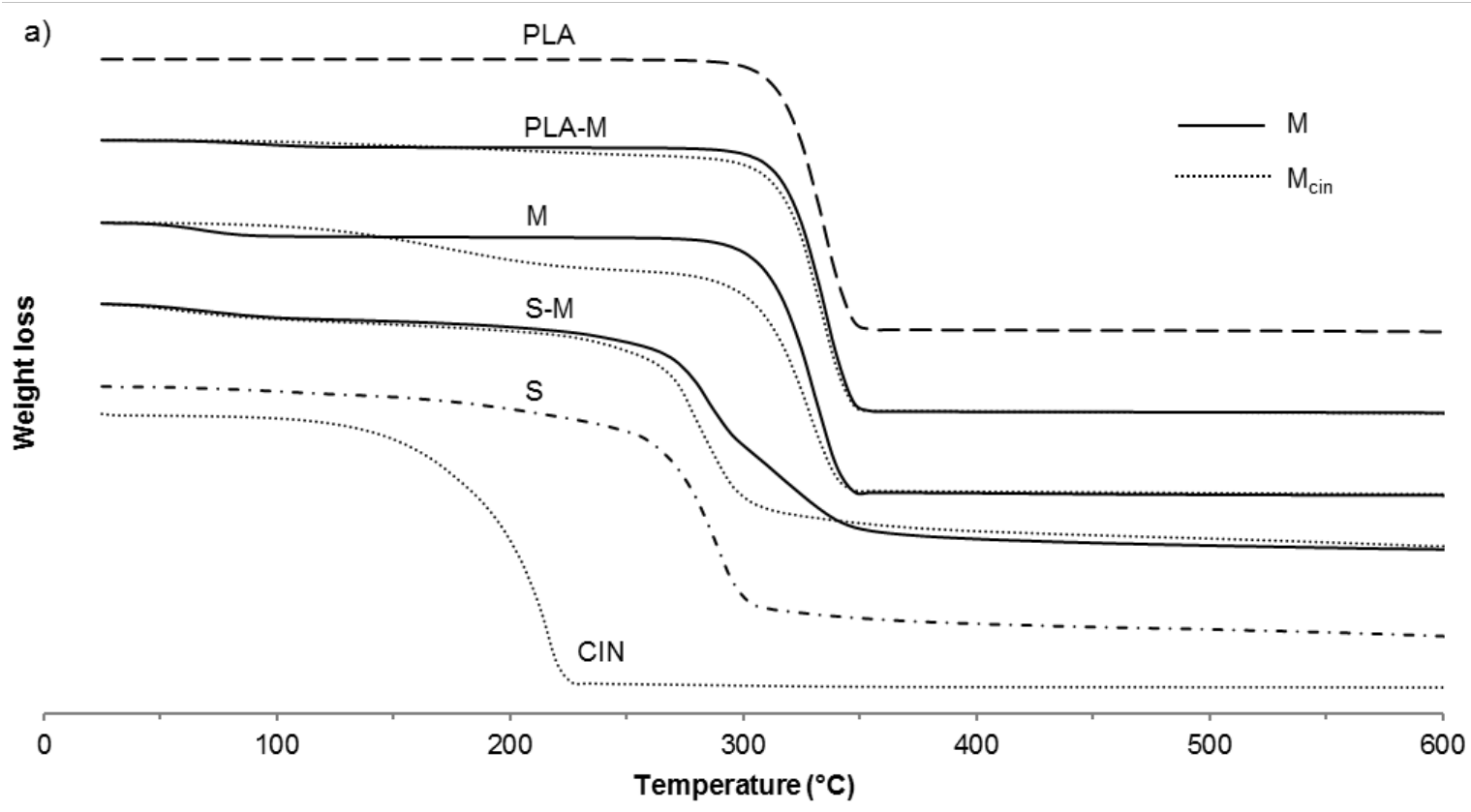




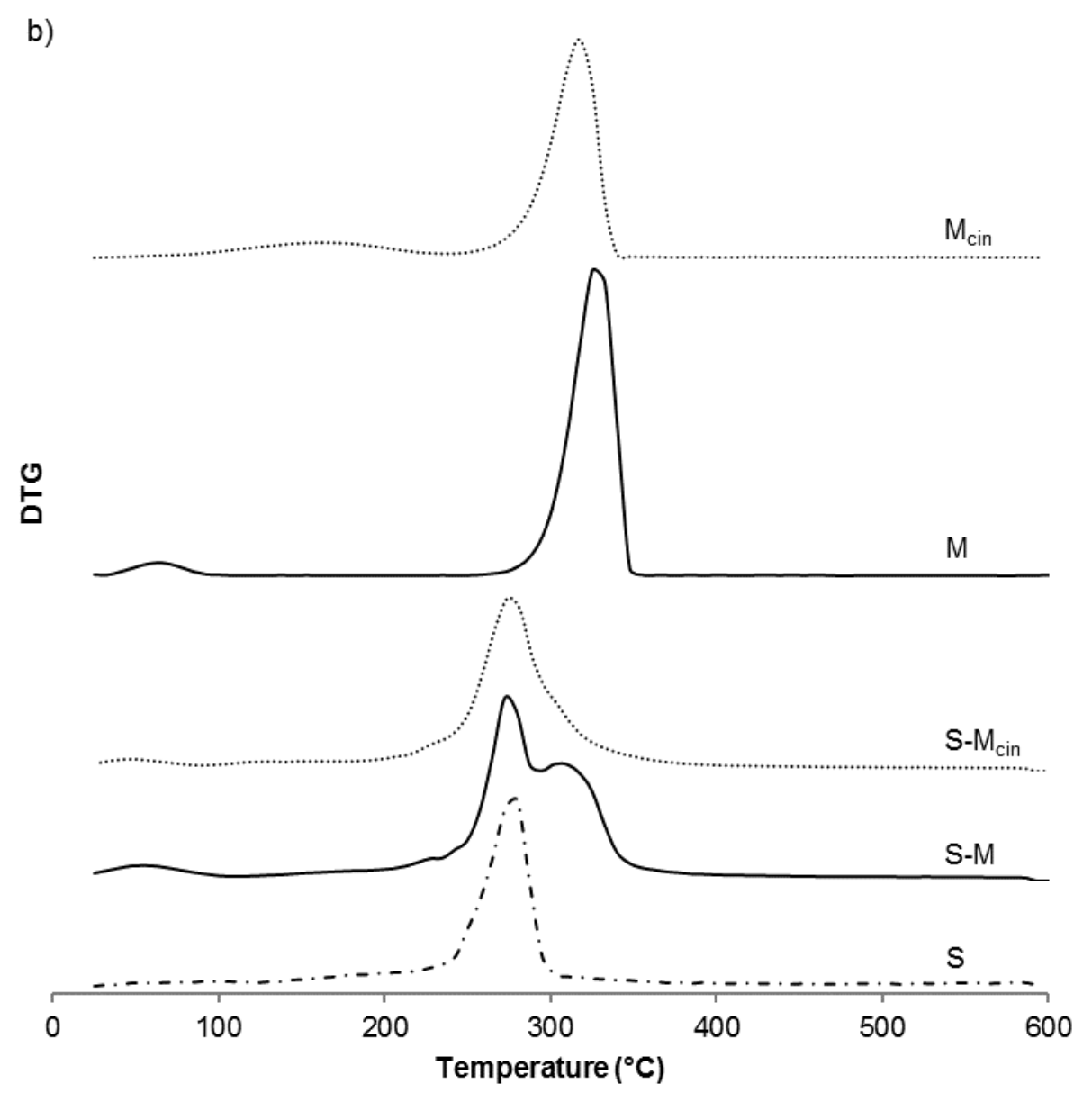

Figure 4.a) Weight loss curves of mono and bilayer films with (dashed lines) and without CIN (continuous line) from TGA analysis, from 25 to $600^{\circ} \mathrm{C}$, also showing the pure $\mathrm{CIN}$ thermal weight loss. b) Derivative curves of starch (S) and amorphous PLA (M) mono and bilayer films with ( $\mathrm{M}_{\text {cin }}$; $\mathrm{S}$ Mcin) and without (S, M; S-M) cinnamaldehyde.

\section{4. Crystallization pattern in the films by X-Ray diffraction analysis}

Figure 5 shows the XRD patterns of film samples. The absence of crystalline peaks for amorphous PLA films is remarkable, regardless of the incorporation of CIN ( $\left.M, M_{\text {cin }}\right)$, as observed by Gorrasi et al. [51] for amorphous PLA. On the other hand, semicrystalline PLA (PLA) showed the characteristic sharp peak at $2 \theta=17^{\circ}$, associated with the helical $10_{3}$ chain of PLA ( $\alpha$-form crystals) [52]. On the contrary, neat starch (S) presented a large amorphous scattering background with small diffraction peaks at $2 \theta=12,13.518 .3,20$ and $20.7^{\circ}$, characteristic of a semicrystalline polymer with a low degree of crystallinity. In thermoplastic corn starch with glycerol, Shi et al. [53] found two peaks at 13.5 and $20.9^{\circ}$ and assigned them to a $\mathrm{V}$-type structure, which is formed by the crystallization of amylose in single helices involving glycerol or lipids. It can be divided into two subtypes, named $\mathrm{V}_{\mathrm{a}}$ (anhydrous) with peaks at $13.2^{\circ}$ and $20.6^{\circ}$ and $V_{h}$ (hydrated) with peaks at $12.6^{\circ}$ and $19.4^{\circ}$ [54]. Yang et al. [55] stressed that $\mathrm{V}_{\mathrm{h}}$-style crystallinity is induced by thermal processing where the strong interaction between hydroxyl groups of starch molecules was substituted by the hydrogen bonds formed between 
the plasticizer and starch during thermoplastic processing. The peak at $18^{\circ}$ is associated with the intermediate form between $V_{h}$ and $V_{a}$ crystallinity (hydrated and anhydrous lattices, respectively), according to Zobel et al. [56]. So, for the obtained thermo-processed starch films, both $V_{h}$ and $V_{a}$ crystallinity was observed. The melting of the crystalline starch fraction was observed in the first heating scan of DSC between $110-200^{\circ} \mathrm{C}$ as a broad endotherm with a temperature peak at about $150^{\circ} \mathrm{C}$, as reported by López et al. [57], coherent with the coexistence of several crystalline forms.

In the X-Ray diffractogram of starch bilayers, a similar dispersion band as that observed in the starch monolayer can be seen, indicating a similar crystallization pattern for the polymer regardless of the adhesion to the amorphous PLA sheet. XRD patterns of PLA bilayers exhibited some difference with respect to semicrystalline PLA, indicating the presence of different crystalline phases. Indeed, a new peak at $2 \theta=19^{\circ}$ was recorded; revealing the presence of $\alpha^{\prime}$-form crystals [49]. This peak showed lower intensity in the PLA-Mcin film, while the amorphous response was intensified. These results suggest that the diffusion of low molecular weight compounds or CIN from the amorphous PLA layer to the semicrystalline PLA during thermocompression slightly modified the crystallization pattern of PLA due to the promotion of chain interactions with these compounds. Thus, more unsTable crystal forms $\left(\alpha^{\prime}\right)$ or crystallization inhibition was observed in PLA bilayers as deduced from the crystallization enthalpy values obtained by DSC.

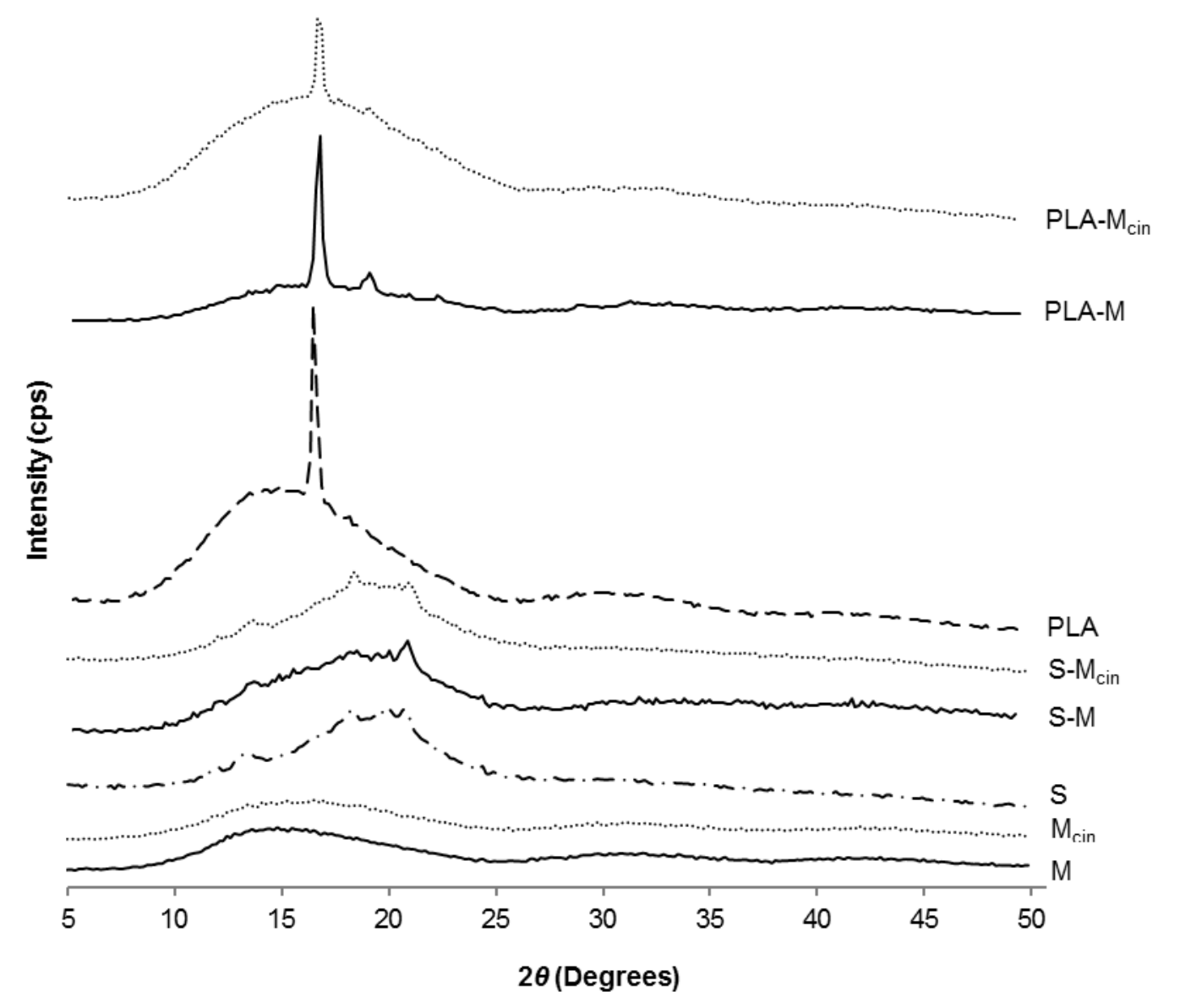

Figure 5. X-Ray Diffraction patterns of starch and PLA mono and bilayer films, with and without cinnamaldehyde. 


\section{5. FTIR spectroscopy}

FTIR analysis was carried out on the films in order to identify interactions between film components, especially when CIN was incorporated. First, it is noticeable that the FTIR patterns of the different replicates of each film formulation exhibited great reproducibility, which indicates a high degree of homogeneity in the films. Figure 6 shows the different spectra, adequately grouped to better analyse the different features. The total correspondence of the spectra of $M$ and $M-S$ (obtained from the $M$ layer) samples is remarkable (Figure 6.a)), revealing no changes at molecular level in amorphous PLA during compression moulding with the starch layer. This points to the absence of S-PLA grafting at the interface, although this process would only involve molecules at the interface, which could not give enough signal intensity. All of the characteristic peaks of PLA were observed in amorphous and semicrystalline PLA spectra in both monolayers (Figure 6.a)) and bilayers (Figure 6.b)). The main peaks correspond to the $-\mathrm{C}=\mathrm{O}$ stretching vibration of the ester group of the polymer $\left(1750 \mathrm{~cm}^{-1}\right)$, the asymmetric and symmetric $-\mathrm{CH}_{3}$ deformation vibrations $\left(1454 \mathrm{~cm}^{-1}\right.$ and $1360 \mathrm{~cm}^{-1}$, respectively), the $\mathrm{C}=\mathrm{O}$ bending $\left(1265 \mathrm{~cm}^{-1}\right)$, the $-\mathrm{C}-\mathrm{O}-\mathrm{C}$ - stretching of the ester groups $\left(1182 \mathrm{~cm}^{-1}\right)$, the $\mathrm{C}-\mathrm{O}$ stretching (1130 and $1088 \mathrm{~cm}^{-1}$ ) and the $-\mathrm{OH}$ bending $\left(1043 \mathrm{~cm}^{-1}\right)$. A peak at $872 \mathrm{~cm}^{-1}$, ascribed to the $-\mathrm{C}-\mathrm{C}$ stretching of the amorphous phase was observed in both PLA films. Nonetheless, the peak at $754 \mathrm{~cm}^{-}$ ${ }^{1}$, associated with the $-\mathrm{C}-\mathrm{C}$ - stretching in the crystalline phase was only seen in the semicrystalline PLA spectrum.

Figure 6.c) shows the FTIR spectra of starch bilayer films from both starch (S-M) and amorphous PLA (M-S) layers. The starch layer spectrum is dominated by a broad band at $3300 \mathrm{~cm}^{-1}$, which is assigned to the stretching vibration modes of $-\mathrm{OH}$ groups belonging to starch, glycerol and adsorbed water [58]. Other characteristic bands of starch can be identified at $2928 \mathrm{~cm}^{-1}$ (C-H stretching), $1650 \mathrm{~cm}^{-1}$ (-OH bending) and 1078-930 cm-1 (C-O stretching), while the peaks at 854, 760 and $570 \mathrm{~cm}^{-1}$ are assigned to swing vibrational absorption peaks of the $\mathrm{C}-\mathrm{H}$ bond of starch [59]; [60]. The characteristic absorption peaks of starch were not modified when starch was adhered to $M$ or $M$ cin layers. This indicates that the potential interactions between starch and PLA chains at the interface are not revealed in the starch FTIR spectrum, nor did the CIN diffusion into the starch sheet affected the vibration modes of its chain chemical bonds.

As concerns the active layers, Figure 6.d) presents the spectra of the amorphous PLA monolayer (M) together with the spectra of $M_{c i n}$ samples from both mono ( $\left.M_{c i n}\right)$ and bilayers ( $M_{c i n}-S$ and $\left.M_{c i n}-P L A\right)$. The spectrum of $M_{\text {cin }}$ films showed the characteristic peaks of $C I N$ at 1680 and $1630 \mathrm{~cm}^{-1}$, associated with the stretching vibration of the aldehyde carbonyl group $(\mathrm{C}=0)$ and the unsaturated vibration peak of the benzene ring, respectively, as observed by other authors [61]; [62]. Another weak intensity peak was seen at $1522 \mathrm{~cm}^{-1}$, corresponding to the aromatic domain of CIN [48]. The same peaks also appeared in $M_{c i n}$-PLA and $M_{c i n}-S$ films, with no change in their intensity, revealing that CIN was efficiently included into the bilayers through the amorphous PLA sheet. No significant peak displacement was observed for CIN signals in the films with respect to the pure compound (as described by other authors, Martinez-Abad et al. [61] and Wen et al. [62], which indicates that CIN interactions with the polymer are not intense enough to modify the molecular group vibration pattern. Then, Van der Waals and hydrophobic interactions between CIN and PLA chains could be assumed. 
The FTIR spectra of the films revealed the major presence of CIN in the amorphous PLA layer in which it was initially included and, although the diffusion of this compound into the starch or semicrystalline PLA sheets could occur, it was not quantitative enough to be evidenced through the reflectance FTIR spectra of the assembled layer. Likewise, the interactions between PLA chains and CIN were not intense enough to modify the typical vibration modes of the respective molecular bonds.
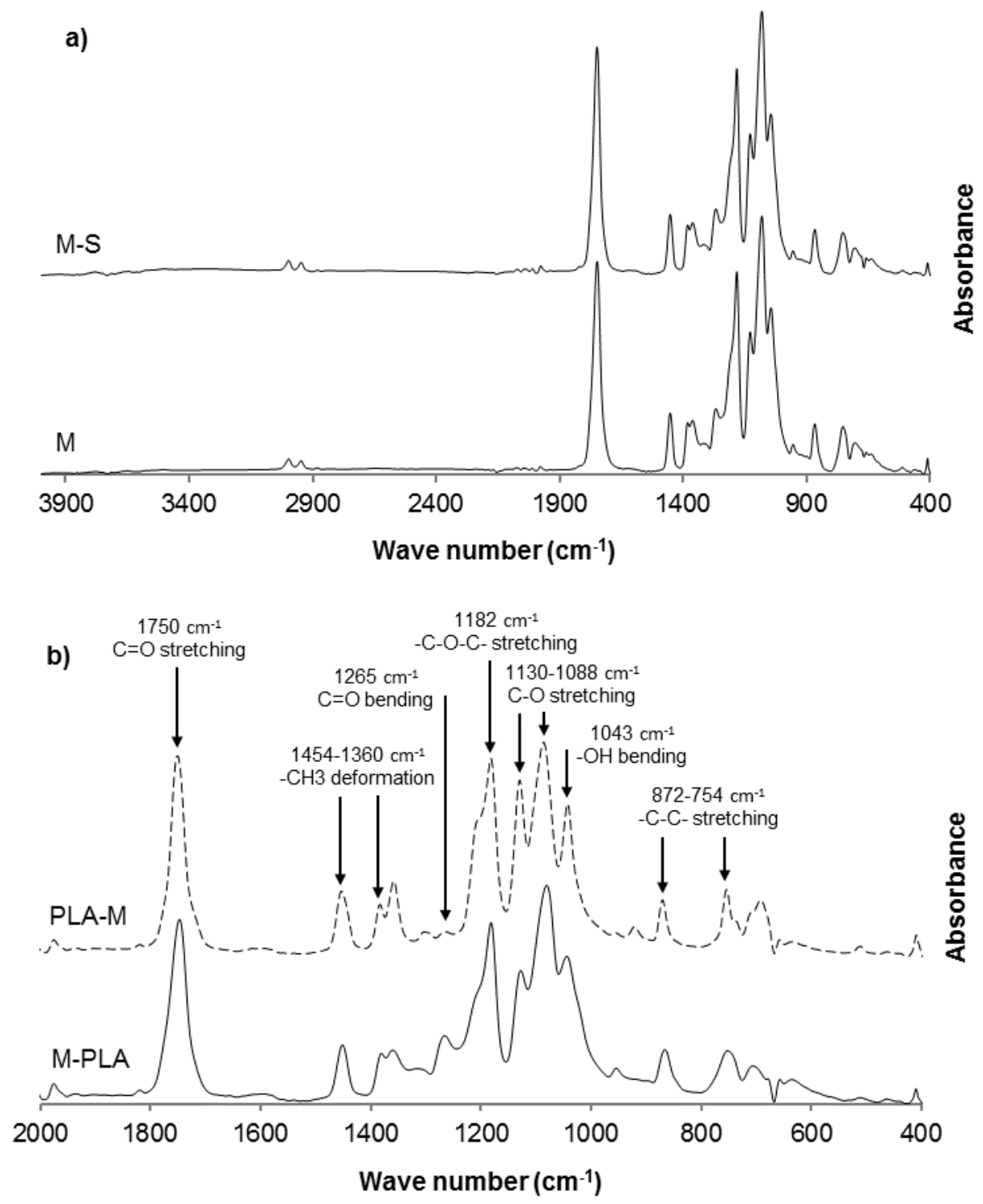

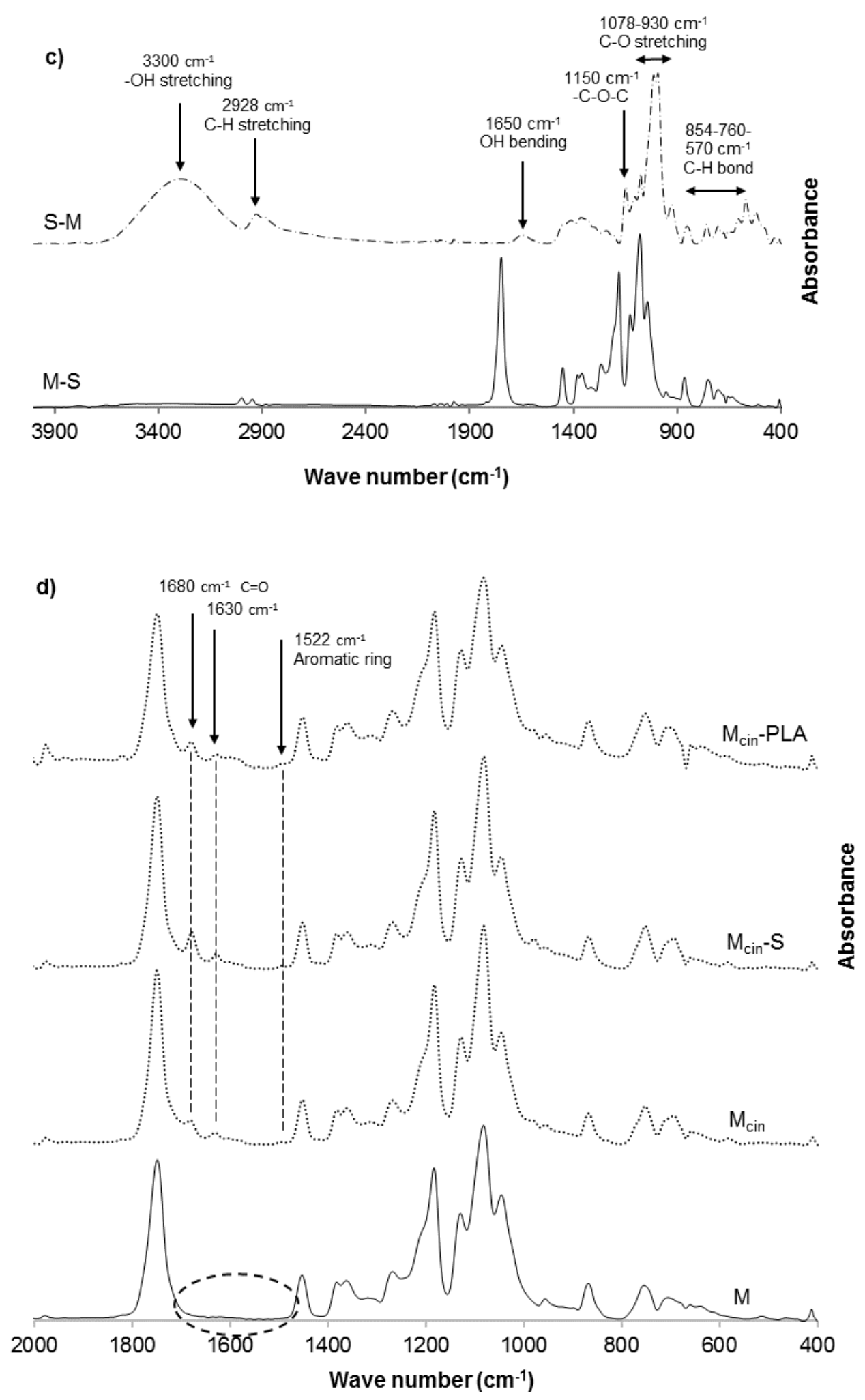

Figure 6. FTIR spectra of film samples a) Amorphous cast PLA (M) and starch bilayer films (M-S) from the M layer. b) PLA bilayer films from both semicrystalline (PLA-M) and amorphous (M-PLA) layers. c) Starch bilayer films from both starch (S-M) and amorphous PLA (M-S) layers. d) Amorphous PLA films with and without CIN in monolayers ( $M$ and $M_{c i n}$ ) and with CIN in bilayers ( $M_{c i n}-S$ and $\left.M_{c i n}-P L A\right)$.

\section{CONCLUSION}


Amorphous PLA-starch bilayer films were successfully obtained by compression moulding of cast PLA layers containing or not cinnamaldehyde, and thermoplastic starch films, with very good adhesion at the interface. Despite the lower ratio of PLA sheet in the bilayer assembly ( $1 / 3$ of the film thickness), a great improvement in the tensile and water vapour barrier properties was achieved with respect to the net starch films (S sample), the films maintaining high transparency and an oxygen permeability as low as that of net starch films. When cinnamaldehyde was included in the cast PLA sheet, films became thinner due to the losses of the volatile active during processing. Nevertheless, the improvement in the barrier properties was maintained but films exhibited lower mechanical resistance. The fitting of the cast layer thickness using a constant polymer surface density ( $\mathrm{g}$ polymer $/ \mathrm{cm}^{2}$ ) could mitigate this problem. PLA bilayers also exhibited lower oxygen permeability than the respective PLA monolayers, which could be associated with the good interfacial adhesion that created additional barrier efficiency. Thermal analysis revealed the diffusion of cinnamaldehyde or low molecular weight compounds from the cast PLA layer to the other sheets (starch or semicrystalline PLA) which contributed to plasticizing the amorphous regions and affected the crystallization pattern of PLA, as also revealed by the X-Ray diffraction analyses. Nevertheless, FTIR spectra did not evidence quantitative amounts of the active in these layers, probably due to the high dilution level of active in these thicker sheets of bilayer. The obtained results offer an interesting option to obtain high barrier-highly resistant active films from thermoplastic starch and amorphous PLA, including cinnamaldehyde in the ethyl acetate solution of the polyester; this solvent being food compatible, which reduces the risks associated with solvent residues and allows for the cold dissolving of amorphous PLA.

\section{ACKNOWLEDGEMENTS}

The authors thank the Ministerio de Economía y Competitividad (Spain) for the financial support provided through Project AGL2013-42989-R and AGL2016-76699-R. Author Justine Muller thanks the Generalitat Valènciana for the Santiago Grisolía Grant (GRISOLIA/2014/003).

\section{REFERENCES}

[1] J. Muller, A. Jiménez, C. González-Martínez, A. Chiralt, Influence of plasticizers on thermal properties and crystallization behaviour of poly (lactic acid) films obtained by compression moulding, Polym. Int. 65 (2016) 970-978.

[2] R.M. Rasal, A.V. Janorkar, D.E. Hirt, Poly (lactic acid) modifications, Prog. Polym. Sci. 35 (2010) 338-356.

[3] M. Hiljanen-Vainio, P. Varpomaa, J. Seppälä, P. Törmälä, Modification of poly (L-lactides) by blending: mechanical and hydrolytic behaviour, Macromol. Chem. Phys. 197 (1996) 1503-1523.

[4] R. Ortega-Toro, A. Muñoz, P. Talens, A. Chiralt, Improvement of properties of glycerol plasticized starch films by blending with a low ratio of polycaprolactone and/or polyethylene glycol, Food Hydrocolloids 56 (2016) 9-19.

[5] A.C. Souza, G.E.O. Goto, J.A. Mainardi, A.C.V. Coelho, C.C. Tadini, Cassava starch composite films incorporated with cinnamon essential oil: Antimicrobial activity, microstructure, mechanical and barrier properties, LWT Food Sci. Technol. 54 (2013) 346-352. 
[6] S. Acosta, A. Jiménez, M. Cháfer, C. González-Martínez, A. Chiralt, Physical properties and stability of starch-gelatin based films as affected by the addition of esters of fatty acids, Food Hydrocolloids 49 (2015) 135-143.

[7] F. Versino, O.V. López, M.A. García, Sustainable use of cassava (Manihot esculenta) roots as raw material for biocomposites development, Ind. Crops Prod. 65 (2015) 79-89.

[8] D.C. Bastos, A.E. Santos, M.L. da Silva, R.A. Simão, Hydrophobic corn starch thermoplastic films produced by plasma treatment, Ultramicroscopy 109 (2009) 1089-1093.

[9] M. Turalija, S. Bischof, A. Budimir, S. Gaan, Antimicrobial PLA films from environment friendly additives, Composites Part B 102 (2016) 94-99.

[10] Z. Xiong, L. Zhang, S. Ma, Y. Yang, C. Zhang, Z. Tang, J. Zhu, Effect of castor oil enrichment layer produced by reaction on the properties of PLA/HDI-g-starch blends, Carbohydr. Polym. 94 (2013) 235-243.

[11] Z. Xiong, Y. Yang, J. Feng, X. Zhang, C. Zhang, Z. Tang, J. Zhu, Preparation and characterization of poly (lactic acid)/starch composites toughened with epoxidized soybean oil, Carbohydr. Polym 92 (2013) 810-816.

[12] Z. Xiong, C. Li, S. Ma, J. Feng, Y. Yang, R. Zhang, J. Zhu, The properties of poly (lactic acid)/starch blends with a functionalized plant oil: Tung oil anhydride, Carbohydr. Polym. 95 (2013) 7784.

[13] W. Phetwarotai, P. Potiyaraj, D. Aht-Ong, Characteristics of Biodegradable Polylactide/Gelatinized Starch Films: Effects of Starch, Plasticizer, and Compatibilizer, J. Appl. Polym. Sci. 126 (2012) 162172.

[14] M.L. Sanyang, S.M. Sapuan, M. Jawaid, M.R. Ishak, J. Sahari, Development and characterization of sugar palm starch and poly (lactic acid) bilayer films, Carbohydr. Polym. 146 (2016) 36-45.

[15] Q. Sun, L. Wang, Z. Lu, Y. Liu, In vitro anti-aflatoxigenic effect and mode of action of cinnamaldehyde against aflatoxin B 1, Int. Biodeterior. Biodegrad. 104 (2015) 419-425.

[16] H. Wang, H. Yuan, S. Li, Z. Li, M. Jiang, Synthesis, antimicrobial activity of Schiff base compounds of cinnamaldehyde and amino acids, Bioorg. Med. Chem. Lett. 26 (2016) 809-813.

[17] F. Xing, H. Hua, J.N. Selvaraj, Y. Zhao, L. Zhou, X. Liu, Y. Liu, Growth inhibition and morphological alterations of Fusarium verticillioides by cinnamon oil and cinnamaldehyde, Food Control 46 (2014) 343-350.

[18] S.A. Baskaran, M.A.R. Amalaradjou, T. Hoagland, K. Venkitanarayanan, Inactivation of Escherichia coli O157: H7 in apple juice and apple cider by trans-cinnamaldehyde, Int. J. Food Microbiol. 141 (2010) 126-129.

[19] M.A.R. Amalaradjou, T.A. Hoagland, K. Venkitanarayanan, Inactivation of Enterobacter sakazakii in reconstituted infant formula by trans-cinnamaldehyde, Int. J. Food Microbiol. 129 (2009) 146-149.

[20] M.A.R. Amalaradjou, S.A. Baskaran, R. Ramanathan, A.K. Johny, A.S. Charles, S.R. Valipe,..., K. Venkitanarayanan, Enhancing the thermal destruction of Escherichia coli O157: H7 in ground beef patties by trans-cinnamaldehyde, Food Microbiol. 27 (2010) 841-844. 
[21] J. Ahmed, M.Z. Mulla, Y.A. Arfat, Thermo-mechanical, structural characterization and antibacterial performance of solvent casted polylactide/cinnamon oil composite films, Food Control 69 (2016) 196204.

[22] S. Makwana, R. Choudhary, N. Dogra, P. Kohli, J. Haddock, Nanoencapsulation and immobilization of cinnamaldehyde for developing antimicrobial food packaging material, LWT Food Sci. Technol. 57 (2014) 470-476.

[23] Y. Qin, J. Yang, J. Xue, Characterization of antimicrobial poly (lactic acid)/poly (trimethylene carbonate) films with cinnamaldehyde, J. Mater. Sci. 50 (2015) 1150-1158.

[24] M.P. Balaguer, G. López-Carballo, R. Catala, R. Gavara, P. Hernandez-Munoz, Antifungal properties of gliadin films incorporating cinnamaldehyde and application in active food packaging of bread and cheese spread foodstuffs, Int. J. Food Microbiol.166 (2013) 369-377.

[25] M.A. Rojas-Graü, R.J. Avena-Bustillos, C. Olsen, M. Friedman, P.R. Henika, O. Martín-Belloso, ..., T.H. McHugh, Effects of plant essential oils and oil compounds on mechanical, barrier and antimicrobial properties of alginate-apple puree edible films, J. Food Eng. 81 (2007) 634-641.

[26] ASTM (1992). Standard methods for tensile properties of thin plastic sheeting. In: Annual book of American Standard Testing Methods. Designation (D882-91). Philadelphia, PA: ASTM

[27] ASTM (1995). Standard test methods for water vapour transmission of materials. Standard designations: E96-95 Annual book of ASTM standards. Philadelphia, PA: American Society for Testing and Materials. (pp. 406-413).

[28] A. Gennadios, C.L. Weller, C.H. Gooding, Measurement errors in water vapor permeability of highly permeable, hydrophilic edible films, J. Food Eng. 21 (1994) 395-409.

[29] ASTM (2014). Standard test method for determination of oxygen gas transmission rate, permeability and permeance at controlled relative humidity through barrier materials using a coulometric detector. Active Standard ASTM F1927, developed by Subcommittee F02.10. American Society for Testing and Materials, West Conshohocken, PA.

[30] J.B. Hutchings, Instrumental specification, in: Springer US, Food colour and appearance, 1999, pp. 199-237.

[31] C. Pastor, L. Sánchez-González, M. Cháfer, A. Chiralt, C. González-Martínez, Physical and antifungal properties of hydroxypropylmethylcellulose based films containing propolis as affected by moisture content, Carbohydr. Polym. 82 (2010) 1174-1183.

[32] ASTM (1999). Standard test methods for specular gloss. Designation (D523): Annual book of ASTM standards (Vol. 06.01) Philadelphia, PA: American Society for Testing and Materials.

[33] K.M. Choi, M.C. Choi, D.H. Han, T.S. Park, C.S. Ha, Plasticization of poly (lactic acid)(PLA) through chemical grafting of poly (ethylene glycol)(PEG) via in situ reactive blending, Eur. Polym. J. 49 (2013) 2356-2364.

[34] M.B. Coltelli, I.D. Maggiore, M. Bertoldo, F. Signori, S. Bronco, F. Ciardelli, Poly (lactic acid) properties as a consequence of poly (butylene adipate-co-terephthalate) blending and acetyl tributyl citrate plasticization, J. Appl. Polym. Sci. 110 (2008) 1250-1262.

[35] Z. Gui, Y. Xu, Y. Gao, C. Lu, S. Cheng, Novel polyethylene glycol-based polyester-toughened polylactide, Mater. Lett. 71 (2012) 63-65. 
[36] I. Pillin, N. Montrelay, Y. Grohens, Thermo-mechanical characterization of plasticized PLA: Is the miscibility the only significant factor?, Polymer 47 (2006) 4676-4682.

[37] E. Fortunati, I. Armentano, Q. Zhou, D. Puglia, A. Terenzi, L.A. Berglund, J.M. Kenny, Microstructure and nonisothermal cold crystallization of PLA composites based on silver nanoparticles and nanocrystalline cellulose, Polym. Degrad. Stab. 97 (2012) 2027-2036.

[38] E. Fortunati, A. Aluigi, I. Armentano F. Morena, C. Emiliani, S. Martino, ..., D. Puglia, Keratins extracted from Merino wool and Brown Alpaca fibres: Thermal, mechanical and biological properties of PLLA based biocomposites, Mater. Sci. Eng., C 47 (2015) 394-406.

[39] M.A. Shirai, J.B. Olivato, P.S. García, C.M.O. Müller, M.V.E. Grossmann, F. Yamashita, Thermoplastic starch/polyester films: effects of extrusion process and poly (lactic acid) addition, Mater. Sci. Eng., C 33 (2013) 4112-4117.

[40] R. Ortega-Toro, A. Jiménez, P. Talens, A. Chiralt, Effect of the incorporation of surfactants on the physical properties of corn starch films, Food Hydrocolloids 38 (2014) 66-75.

[41] J. Bonilla, E. Talón, L. Atarés, M. Vargas, A. Chiralt, Effect of the incorporation of antioxidants on physicochemical and antioxidant properties of wheat starch-chitosan films, J. Food Eng. 118 (2013) 271-278.

[42] M. Schmid, K. Dallmann, E. Bugnicourt, D. Cordoni, F. Wild, A. Lazzeri, K. Noller, Properties of whey-protein-coated films and laminates as novel recyclable food packaging materials with excellent barrier properties, Int. J. Polym. Sci. 8 (2012) 1-7.

[43] R. Auras, B. Harte, S. Selke, An overview of polylactides as packaging materials, Macromol. Biosci. 4 (2004) 835-864.

[44] H. Cai, V. Dave, R.A. Gross, S.P. McCarthy, Effects of physical aging, crystallinity, and orientation on the enzymatic degradation of poly (lactic acid), J. Polym. Sci., Part B: Polym. Phys. 34 (1996) 2701-2708.

[45] R. Acioli-Moura, X.S. Sun, Thermal degradation and physical aging of poly (lactic acid) and its blends with starch, Polym. Eng. Sci. 48 (2008) 829-836.

[46] M. Yasuniwa, K. Sakamo, Y. Ono, W. Kawahara, Melting behavior of poly (I-lactic acid): X-ray and DSC analyses of the melting process, Polymer 49 (2008) 1943-1951.

[47] R. Ortega-Toro, J. Contreras, P. Talens, A. Chiralt, Physical and structural properties and thermal behaviour of starch-poly ( $\varepsilon$-caprolactone) blend films for food packaging, Food Packaging and Shelf Life 5 (2015) 10-20.

[48] J. Ahmed, N. Hiremath, H. Jacob, Antimicrobial, rheological, and thermal properties of plasticized polylactide films incorporated with essential oils to Inhibit Staphylococcus aureus and Campylobacter jejuni, J. Food Sci. 81 (2016) 419-429.

[49] J.P. Kalish, K. Aou, X. Yang, S.L. Hsu, Spectroscopic and thermal analyses of $\alpha^{\prime}$ and $\alpha$ crystalline forms of poly (I-lactic acid), Polymer 52 (2011) 814-821.

[50] C.M. Jaramillo, T.J. Gutiérrez, S. Goyanes, C. Bernal, L. Famá, Biodegradability and plasticizing effect of yerba mate extract on cassava starch edible films, Carbohydr. Polym. 151 (2016) 150-159. 
[51] G. Gorrasi, R. Pantani, Effect of PLA grades and morphologies on hydrolytic degradation at composting temperature: assessment of structural modification and kinetic parameters, Polym. Degrad. Stab. 98 (2013) 1006-1014.

[52] J. Hughes, R. Thomas, Y. Byun, S. Whiteside, Improved flexibility of thermally sTable poly-lactic acid (PLA), Carbohydr. Polym. 88 (2012) 165-172.

[53] R. Shi, Q. Liu, T. Ding, Y. Han, L. Zhang, D. Chen, W. Tian, Ageing of soft thermoplastic starch with high glycerol content, J. Appl. Polym. Sci. 103 (2007) 574-586.

[54] E. Corradini, L.C. de Morais, N.R. Demarquette, J.A. Agnelli, L.H. Mattoso, Study of process parameters for starch, gluten, and glycerol mixtures, Polym. Adv. Technol. 18 (2007) 861-867.

[55] J.H. Yang, J.G. Yu, X.F. Ma, Study on the properties of ethylenebisformamide and sorbitol plasticized corn starch (ESPTPS), Carbohydr. Polym. 66 (2006) 110-116.

[56] H.F. Zobel, A.D. French, M.E. Hinkle, X-Ray diffraction of oriented amylose fibers. II. Structure of $\checkmark$ amyloses, Biopolymers 5 (1967) 837-845.

[57] O. López, M.A. García, M.A. Villar, A. Gentili, M.S. Rodriguez, L. Albertengo, Thermocompression of biodegradable thermoplastic corn starch films containing chitin and chitosan, LWT Food Sci. Technol. 57 (2014) 106-115.

[58] L. Fama, A.M.B. Bittante, P.J. Sobral, S. Goyanes, L.N. Gerschenson, Garlic powder and wheat bran as fillers: Their effect on the physicochemical properties of edible biocomposites, Mater. Sci. Eng., C 30 (2010) 853-859.

[59] L. Castillo, O. López, C. López, N. Zaritzky, M.A. García, S. Barbosa, M. Villar, Thermoplastic starch films reinforced with talc nanoparticles, Carbohydr. Polym. 95 (2013) 664-674.

[60] Y. Hu, Q. Wang, M. Tang, Preparation and properties of Starch-g-PLA/poly (vinyl alcohol) composite film, Carbohydr. polym. 96 (2013) 384-388.

[61] A. Martínez-Abad, G. Sánchez, V. Fuster, J.M. Lagaron, M.J. Ocio, Antibacterial performance of solvent cast polycaprolactone (PCL) films containing essential oils, Food Control 34 (2013) 214-220.

[62] P. Wen, D.H. Zhu, H. Wu, M.H. Zong, Y.R. Jing, S.Y. Han, Encapsulation of cinnamon essential oil in electrospun nanofibrous film for active food packaging, Food Control 59 (2016) 366-376. 